\title{
Relação entre abastecimento de água e indicadores epidemiológicos na região metropolitana de Belém
}

\author{
Relationship between water supply and epidemiological indicators in the metropolitan region of \\ Belém \\ Relación entre el suministro de agua e indicadores epidemiológicos en la región metropolitana de \\ Belém
}

Letícia Picanço da Silva

ORCID: https://orcid.org/0000-0003-1744-003X Universidade do Estado do Pará, Brasil E-mail: leticiapicanco@hotmail.com Otávio Silva de Jesus ORCID: https://orcid.org/0000-0001-9294-7899 Universidade do Estado do Pará, Brasil

E-mail: otavios.j@hotmail.com

João Paulo Sousa da Silva

ORCID: https://orcid.org/0000-0001-7174-0389 Universidade do Estado do Pará, Brasil E-mail: joaopaulojoao482@gmail.com

Felipe da Silva Sousa

ORCID: https://orcid.org/0000-0001-5095-2999 Universidade do Estado do Pará, Brasil

E-mail: felipesouza440@gmail.com

Camila Nascimento Alves

ORCID: https://orcid.org/0000-0001-5093-7078 Universidade do Estado do Pará, Brasil

E-mail: Camila.alves@uepa.br

Francianne Vieira Mourão

ORCID: https://orcid.org/0000-0001-5651-5407 Universidade do Estado do Pará, Brasil

E-mail: francianne.eng.ambiental@gmail.com

Rodolfo Pereira Brito

ORCID: https://orcid.org/0000-0002-0393-5181 Universidade do Estado do Pará, Brasil E-mail: professor@pereirabrito.com

\begin{abstract}
Resumo
A ausência ou insuficiência de serviços de abastecimento de água pode comprometer a saúde e bem-estar da sociedade, principalmente nas regiões mais pobres. Dentre as doenças de veiculação hídrica, as diarreias e gastroenterites mostram grande relevância no cenário epidemiológico por envolverem índices significativos de morbidade e mortalidade, em especial entre os grupos mais vulneráveis da população. Assim, o estudo teve o objetivo de analisar a cobertura de abastecimento de água e a relação com a incidência de internações por doenças diarreicas e gastroenterites na Região Metropolitana de Belém. Para isso, foi realizada revisão bibliográfica e documental, e os dados foram obtidos nas plataformas do Sistema Nacional de Informações sobre Saneamento (SNIS), do Instituto Brasileiro de Geografia e Estatística (IBGE) e do Departamento de Informática do Sistema Único de Saúde (DataSUS), cujo tratamento foi efetuado em software GIS para geração de mapas temáticos. A análise dos dados obtidos permitiu inferir a dificuldade de universalização do acesso a serviços de abastecimento de água enfrentada pelos municípios da RMB, onde três $(\mathrm{n}=42,9 \%)$ apresentaram um cenário ruim de abastecimento, e apenas um $(\mathrm{n}=14,3 \%)$ apresentou um cenário muito bom. Também foi constatada incidência expressiva de internações por doenças diarreicas e gastroenterites, sobretudo nos municípios de Belém e Marituba, o que pode ser reflexo dos baixos níveis de cobertura de abastecimento água, bem como da má gestão e ineficiência dos sistemas existentes. Portanto, os resultados obtidos podem servir como subsídio para estudos futuros e para tomada de decisão e adoção de medidas interventivas por gestores públicos.
\end{abstract}

Palavras-chave: Atendimento público de água; Doenças diarreicas e gastroenterites; Sistema de informação. 


\begin{abstract}
The lack or insufficiency of water supply services can compromise the health and well-being of society, especially in the poorest regions. Among waterborne diseases, diarrhea and gastroenteritis show great relevance in the epidemiological scenario because they involve significant rates of morbidity and mortality, especially among the most vulnerable groups of the population. Thus, the study aimed to analyze the coverage of water supply and the relation with the incidence of hospitalizations for diarrheal diseases and gastroenteritis in the Metropolitan Region of Belém. For this, it was made a bibliographic and documentary review, and the data were obtained at platforms of the National Sanitation Information System (SNIS), the Brazilian Institute of Geography and Statistics (IBGE) and the Department of Informatics of the Unified Health System (DataSUS), which were processed using GIS software to create thematic maps. The analysis of the data obtained allowed to infer the difficulty of universal access to water supply services faced by the municipalities of the MRB, which three of them $(n=42.9 \%)$ presented a poor scenario, and only one $(n=14,3)$ presented a really good scenario. There was also a significant incidence of hospitalizations for diarrheal diseases and gastroenteritis, especially in Belém and Marituba, which may reflect the low levels of water supply coverage, as well as the poor management and inefficiency of the systems. Therefore, the results can serve as a subsidy for future studies and for decision-making and adoption of intervention measures by public managers.
\end{abstract}

Keywords: Public water service; Diarrheal diseases and gastroenteritis; Information system.

\title{
Resumen
}

La ausencia o insuficiencia de los servicios de abastecimiento de agua puede comprometer la salud y el bienestar de la sociedad, especialmente en las regiones más pobres. Entre las enfermedades de transmisión hídrica, la diarrea y la gastroenteritis cobran gran relevancia en el escenario epidemiológico, ya que involucran importantes tasas de morbilidad y mortalidad, especialmente entre los grupos más vulnerables de la población. Así, el estudio tuvo como objetivo analizar la cobertura del abastecimiento de agua y la relación con la incidencia de hospitalizaciones por enfermedades diarreicas y gastroenteritis en la Región Metropolitana de Belém. Plataformas del Sistema Nacional de Información de Saneamiento (SNIS), Instituto Brasileño de Geografía y Estadística. (IBGE) y el Departamento de Informática del Sistema Único de Salud (DataSUS), que fueron procesados mediante software GIS para generar mapas temáticos. El análisis de los datos obtenidos permitió inferir la dificultad de universalizar el acceso a los servicios de abastecimiento de agua que enfrentan los municipios de la RMB, donde tres $(\mathrm{n}=42,9 \%)$ tenían un escenario de mal abastecimiento, y solo uno $(\mathrm{n}=14,3 \%)$ presentó un escenario muy bueno. También se encontró una incidencia significativa de hospitalizaciones por enfermedades diarreicas y gastroenteritis, especialmente en los municipios de Belém y Marituba, lo que puede ser reflejo de los bajos niveles de cobertura de abastecimiento de agua, así como del mal manejo e ineficiencia de los sistemas existentes. Por tanto, los resultados obtenidos pueden servir de subvención para futuros estudios y para la toma de decisiones y la adopción de medidas de intervención por parte de los gestores públicos.

Palabras clave: Servicio público de agua; Enfermedades diarreicas y gastroenteritis; Sistema de información.

\section{Introdução}

A adequação e universalização de serviços, estabelecidas pela Política Nacional de Saneamento Básico, recentemente alterada com a aprovação da Lei n ${ }^{\circ} 14.026$ de 2020 (Brasil, 2020), objetivam a manutenção da qualidade de vida da população. Porém, o controle sanitário-ambiental e a acessibilidade de serviços previstos nessa lei representam um grande desafio visto todos os problemas infraestruturais ocasionados pela brusca expansão urbana e o crescimento populacional pelo qual o país passou a partir da década de 70 (Gomes, 2019, Santos, Berticelli, Fritsch, 2018).

Neste sentido, os prejuízos à saúde pública relacionam-se diretamente à inexistência ou fragilidade da prestação do conjunto de serviços e instalações de: abastecimento de água potável, esgotamento sanitário, limpeza urbana e manejo de resíduos sólidos e drenagem e manejo das águas pluviais urbanas (Landau, Moura, 2016), conceituados pela PNSB e tidos como os componentes do saneamento básico.

Embora o contexto do abastecimento de água apresente as condições mais favoráveis dentre esses componentes, ressalta-se que a ineficiência desse serviço e as más condições sanitárias da água são alguns dos principais problemas ambientais enfrentados pela população, pois está diretamente ligado à instabilidade da saúde dos indivíduos, especialmente dos grupos mais vulneráveis e de regiões mais pobres. Em outras palavras, a água se torna um veículo de agentes infecciosos que impactam consideravelmente a saúde e bem-estar das pessoas (Carvalho, Rocha, 2020).

Nesse contexto, em relação aos dados inerentes à saúde pública, de acordo com o disponibilizado pelo Instituto Trata Brasil, o número de internações totais por doenças de veiculação hídrica no Brasil, em 2018, foi de mais 233 mil, sendo que só 
a região Norte registrou o equivalente a quase 41 mil casos (Instituto trata Brasil, 2018).

Entre essas doenças, a Organização Mundial de Saúde (OMS) destaca as doenças diarreicas e gastroenterites como uma das maiores dificuldades enfrentadas pela saúde pública, visto que são uma das principais causas de morbidade e mortalidade infantil (Howard et al., 2020). Isto reflete as condições precárias e o insuficiente atendimento da população quanto aos serviços de saneamento, em especial ao fornecimento de água com qualidade inadequada para consumo (Albuquerque et al., 2020).

Tendo em vista que fatores como o nível de cobertura de serviços de abastecimento de água potável, higiene e gestão eficaz de recursos hídricos são imprescindíveis para o alcance de melhorias no contexto de prevenção da carga global de doenças (Vieira, 2020), faz-se necessário a realização de estudos que possibilitem a investigação de condições sanitárias, ambientais e de saúde no intuito de fomentar a elaboração de políticas públicas e planejamento, melhorias na gestão de serviços e o direcionamento eficiente de investimentos (Marinho, Pontes, Bichara, 2020).

Ressalta-se ainda a relevância dessa análise em localidades que apresentam maiores dificuldades infraestruturais e alta incidência de doenças, como é o caso de municípios região Norte, que demonstram possuir consideráveis deficiências quantos aos serviços de saneamento ambiental, além do elevado registro de casos de internações por doenças relacionadas ao saneamento ambiental inadequado (Aguiar et al., 2020).

Isso pode envolver a análise conjunta de dados referentes a condições sanitário-ambientais e de saúde pública. Nesse sentido, os Sistemas de Informações Geográficas (SIG) utilizam-se de técnicas e ferramentas de geoprocessamento no intuito de facilitar essa compreensão e interpretação de situações (Peixoto et al., 2017).

Esse tipo de aplicação técnica pode servir de subsídio tanto para a equipe de gestão municipal quanto para estudos vindouros, a fim de promover maior segurança quanto à tomada de decisões, às intervenções em cada localidade e à manutenção da qualidade de vida e do meio ambiente (Gomes, Mendonça, Cavalcante, 2019, Silva et al., 2019).

Portanto, o objetivo da pesquisa é conhecer a relação entre a efetividade de políticas públicas municipais, informações inerentes ao abastecimento de água e a incidência de internações por doenças diarreicas e gastroenterites na Região Metropolitana de Belém.

\subsection{Objetivos}

\subsubsection{Geral}

Conhecer a relação entre a efetividade de políticas públicas municipais, informações inerentes ao abastecimento de água e a incidência de internações por doenças diarreicas e gastroenterites na Região Metropolitana de Belém.

\subsubsection{Específicos}

- Conhecer as diretrizes de políticas públicas por meio da identificação da existência de planos e políticas municipais de saneamento básico;

- Relacionar o índice de abastecimento de água com a incidência de internações de doença diarreicas e gastroenterites;

- $\quad$ Realizar a classificação de cenários e espacialização de variáveis;

\section{Revisão Bibliográfica}

\subsection{Panorama dos serviços de abastecimento de água potável}

O consumo de água sem o devido tratamento pode se associar a efeitos negativos no organismo humano, o que pode levar à fatalidade. Nesse sentido, a importância da potabilidade da água para todos foi incorporada pela ONU em 2010, ao declarar a água limpa e segura e ao saneamento básico como um direito humano fundamental (ONU, 2010), e em 2015, na elaboração dos Objetivos de Desenvolvimento Sustentável (ODS), onde o Objetivo $n^{\circ}$ 6, que dispõe sobre a garantia da 
disponibilidade e manejo sustentável da água e saneamento, estabelece a busca pela universalização e equidade do acesso à água segura até o ano de 2030 (ONU, 2015).

De acordo com Art. 23 da Constituição Federal do Brasil, cabe à União, aos Estados, ao Distrito Federal e aos Municípios promoverem a melhoria das condições de saneamento básico, bem como o abastecimento de água potável, proteger o meio ambiente e combater a poluição em qualquer de suas formas (Brasil, 1988).

Nesse viés, também a Política Nacional de Saneamento básico, instituída pela Lei nº 14.026/2020 estabelece que as instalações e equipamentos devem fornecer água com qualidade, regularidade e tendo em conta a universalização do acesso e efetiva prestação do serviço (Brasil, 2020). Para isso, a PNSB também define a elaboração do Plano Municipal de Saneamento básico como obrigatória a todos os municípios e a condição que permite o repasse de recursos da União (Brasil, 2020).

No que diz respeito ao cenário legislativo referente à qualidade da água direcionada ao abastecimento público, o Ministério da Saúde, através da Portaria de Consolidação no 05, Anexo XX, estabelece diretrizes quanto ao controle e vigilância da qualidade da água para consumo humano, distribuída por meio de sistema ou solução alternativa coletiva ou individual de abastecimento, e seu padrão de potabilidade. Para essa finalidade, a água deve apresentar boa qualidade físico-química, microbiológica e organoléptica, sem que ofereça riscos à saúde humana (Brasil, 2017a).

Porém, embora seja indispensável para saúde e bem-estar, a garantia da água em quantidade e qualidade ideais para todos constitui um dos principais desafios enfrentados pelo Brasil em decorrência de problemas de provisão, degradação ambiental e aumento crescente da população e, por consequência, da demanda hídrica (Maia, 2017).

No que tange ao panorama de atendimento público de água, conforme dados divulgados pelo Sistema Nacional de Informações de Saneamento (2018), o índice de abastecimento de água no Brasil no ano de 2018 era de 83,6\%, o que se traduzia em cerca de 40,4 milhões de brasileiros sem acesso a água, sendo que, na região Norte, o percentual foi superior a $40 \%$ de habitantes sem acesso a esse serviço, consistindo no percentual mais alto dentre todas as regiões do país (Quadro 1). Nesse mesmo ano, o estado do Pará apresentou um índice de 45,6\% de abastecimento de água.

Quadro 1. Panorama de abastecimento de água nas regiões do Brasil em 2018.

\begin{tabular}{|c|c|c|c|}
\hline Região & $\begin{array}{c}\text { Extensão territorial }\left(\mathbf{k m}^{\mathbf{2}}\right) \\
\text { (IBGE) }\end{array}$ & $\begin{array}{c}\text { População total residente (hab) }-\mathbf{2 0 1 8} \\
\text { (IBGE) }\end{array}$ & $\begin{array}{c}\text { Índice de Abastecimento de Água }(\boldsymbol{\%}) \\
\text { (SNIS) }\end{array}$ \\
\hline Centro-Oeste & 1.606 .371 & 16.085 .885 & 89,0 \\
\hline Nordeste & 1.554 .257 & 56.760 .780 & 74,2 \\
\hline Norte & $\mathbf{3 . 8 5 3 . 3 2 7}$ & $\mathbf{1 8 . 1 8 2 . 2 5 3}$ & $\mathbf{5 7 , 1}$ \\
\hline Sudeste & 924.511 & 87.711 .946 & 91,2 \\
\hline Sul & 576.409 & 29.754 .036 & 90,2 \\
\hline
\end{tabular}

Fonte: IBGE (2018); SNIS (2018).

Ainda no contexto da região Norte, não se desconsidera a abundância de recursos naturais, onde se destaca a disponibilidade hídrica que a região compreende. Ela, somada ao fato de a localidade abranger a menor densidade demográfica do Brasil, também instalam uma contradição de acesso a água potável, o que pode revelar a má gestão de recursos hídricos, a ineficiência dos sistemas de abastecimento de água e a influência de determinantes socioeconômicos (Bordalo, 2017).

Dessa forma, embora os dispositivos jurídicos determinem a busca pelo acesso universal dos serviços de abastecimento de água, a realidade se distancia do ideal. Nesse contexto, ressalta-se que a população de baixa renda, a que reside em áreas periféricas e os moradores de áreas rurais são os mais afetados pelas deficiências ou ausência dos serviços essenciais de saneamento básico (Ferreira et al., 2016).

O cenário de abastecimento de água enfrenta dificuldades de efetivação dos serviços, o que implica na redução da 
qualidade de vida e aumento significativo de gastos com a saúde pública. Quanto a essa questão, é de responsabilidade do poder público a análise e mitigação das situações-problema e a promoção da ampla distribuição de água, de forma a cumprir o direito fundamental de acesso a água de forma adequada para satisfação, saúde e conforto de todos (Maia, 2017).

\subsection{Doenças diarreicas e gastroenterites}

A inexistência ou ineficácia de serviços de saneamento prejudicam a saúde e qualidade de vida da população. Nesse sentido, em relação às principais consequências negativas decorrentes da inadequação dos serviços, pode-se relacionar a transmissão de doenças e a poluição ambiental (Santos et al., 2018).

De acordo com informações disponibilizadas pelo Departamento de Informática do Sistema Único de Saúde (DATASUS), em 2018, o número de casos registrados de internações por doenças de veiculação hídrica no Brasil foi equivalente a mais de 230 mil, sendo o número de óbitos registrados maior que 2 mil (Datasus, 2018).

No que diz respeito às principais formas de disseminação dessas doenças, ressaltam-se o consumo de água cujas características não conferem segurança, o que decorre da utilização de fontes alternativas de consumo ou da ineficiência dos sistemas de abastecimento público, e as condições insuficientes de higiene (Vieira, 2020).

Dentre as doenças de veiculação hídrica, as doenças diarreicas e gastroenterites apresentam um problema relevante no setor de saúde pública. Isso porque envolvem expressivos índices de morbidade e mortalidade, em especial entre crianças e lactantes, que configuram grupos mais vulneráveis da população (Dairo; Ibrahim; Salawu, 2017; Howard et al., 2020; Soboksa et al., 2021).

Elas podem ser caracterizadas pela diminuição da consistência das fezes e aumento da frequência de evacuações (sendo de no mínimo três ocorrências em um intervalo de tempo de 24h), causando um desequilíbrio na absorção de nutrientes pelo organismo. Além disso, pode seguir de outros sintomas como náuseas, febre e dor abdominal. As complicações relacionadas consistem em: desidratação e disfunção hidroeletrolítica, choque hipovolêmico e hipopotassemia (Brasil, 2017b).

Em relação ao cenário de incidência do doenças diarreicas, de acordo com o Instituto Trata Brasil, com base nos dados divulgados pelo DataSUS, em 2018, o Brasil apresentou mais de 210 mil casos de internação por doenças diarreicas, sendo que a região Norte representou cerca de 17,6\% desse registro (Quadro 2). Nesse mesmo ano o Pará apresentou quase 27 mil casos da doença.

Quadro 2. Panorama de internações por doenças de veiculação hídrica nas regiões do Brasil em 2018.

\begin{tabular}{|c|c|c|}
\hline Região & $\begin{array}{c}\text { Internações por doenças de veiculação } \\
\text { hídrica (Número de internações) }\end{array}$ & $\begin{array}{c}\text { Internações por diarreia } \\
\text { (Número de internações) }\end{array}$ \\
\hline Centro-Oeste & 19.271 & 13.472 \\
\hline Nordeste & 109.072 & 102.214 \\
\hline Norte & $\mathbf{4 0 . 9 1 5}$ & $\mathbf{3 7 . 2 9 2}$ \\
\hline Sudeste & 39.723 & 34.791 \\
\hline Sul & 24.899 & 23.835 \\
\hline
\end{tabular}

Fonte: DataSUS (2018); Instituto Trata Brasil (2018).

É importante ressaltar que as insuficiências inerentes ao setor de saneamento básico, principalmente no que tange ao abastecimento de água potável e o esgotamento sanitário, refletidas no ocorrência de expressivos números de casos de contaminação por doenças diarreicas, em especial no Norte e Nordeste, acarreta ainda consequências negativas sobre o sistema econômico, com a imprescindibilidade de gastos elevados para combater doenças relacionadas às condições sanitárias precárias (Santos et al., 2018). 
A falta de atenção voltada para os serviços de saneamento básico propicia encadeamentos negativos na saúde humana. Entretanto, embora a questão do alto número de doenças diarreicas gere um significativo efeito sobre a saúde pública, poucos são os estudos que objetivam a realização da análise ambiente-saúde (Oliveira et al. 2020).

\subsection{Região Metropolitana de Belém}

A Região Metropolitana de Belém (RMB) provém do conjunto de oito regiões metropolitanas brasileiras pioneiras. Elas foram definidas a partir da Lei Federal no 14, de 8 de junho de 1973, visto a acelerada expansão urbana de grandes municípios para além dos limites institucionais e as crescentes demandas criadas (Silva, 2017).

$\mathrm{Na}$ época, a RMB era composta apenas por Belém e Ananindeua, entretanto, mudanças ocorridas nos anos seguintes reajustaram esses limites territoriais (Pinheiro; Ponte, 2021). Atualmente a RMB é constituída pelos seguintes municípios: Ananindeua, Belém, Benevides, Castanhal, Marituba, Santa Bárbara e Santa Izabel.

Apesar de não existir um órgão particular que seja incumbido das responsabilidades sobre as relações interfederativas, como estabelecido pelo Estatuto da Metrópole, a Lei Complementar Estadual n 8.096/2015 define que a Secretaria de Desenvolvimento Urbano e Obras Públicas (SEDOP), através da sua Diretoria de Planejamento Metropolitano e Gestão Territorial (Dimet), é responsável pelo diagnóstico e realização de estudos técnicos, coordenação, elaboração e monitoramento de políticas de organização urbana e regional (Pará, 2015).

Contudo, a RMB apresenta indicadores urbanísticos, habitacionais e infraestruturais preocupantes (Ponte et al., 2020). Quanto ao saneamento básico, o perfil encontrado na RMB não difere do padrão da região Norte: deficitário e intrinsicamente atado ao sistema de gestão pública defeituoso, principalmente no que se refere ao lançamento de esgoto sem tratamento e à precariedade quanto ao serviço de abastecimento água potável para consumo humano (Trindade et al, 2017).

Dessa forma, as problemáticas resultantes da ausência ou deficiência de um sistema de saneamento básico podem ser reveladas frequentemente como principais responsáveis pelo agravamento no cenário de casos de doenças, o que implica na saúde, segurança e bem-estar da sociedade. Além disso, não se desconsidera as interações e influências de fatores ambientais e socioeconômicos no acometimento da saúde pública de determinada localidade, além das condições sanitárias (Holanda et al., 2020).

\subsection{Geoprocessamento e mapeamento temático}

A tecnologia tornou-se instrumento essencial em estudos de planejamento urbano e ambiental. Nesse sentido, o avanço de sistemas de informação propiciou o surgimento de métodos de estruturação de informações geográficas que facilitam a compreensão das configurações de um território em um contexto espacial (Castro; Rodrigues; Ferreira filho, 2020).

Como exemplo disso, destaca-se a geração de elementos cartográficos e o mapeamento espacial temático em softwares de informação geográfica, sendo considerados ferramentas versáteis e eficientes de comunicação (Araújo; Anjos; Rocha-Filho, 2017).

Isso porque o tratamento de dados ambientais a partir desses recursos computacionais permite o cruzamento e a sobreposição de informações de diferentes fontes, e a principal relevância prevalece na praticidade, rapidez e acessibilidade de resultados, tanto no universo profissional quanto no público (Singh, 2019).

A partir dessa análise, é possível obter a visualização espacial de determinado cenário, o que fomenta a formulação de hipóteses, a interpretação e a explicação de fenômenos (Cardoso et al., 2020). Tal subsídio contribui de forma positiva com processos de ordenamento territorial, planejamento e a gestão de medidas a serem adotadas por parte de agentes tomadores de decisões (Catete et al., 2017). 


\section{Metodologia}

\subsection{Método da Pesquisa}

O método a ser aplicado neste estudo é o descritivo (Leão, 2017), uma vez que visa descrever e caracterizar a área estudada por classificação de cenários de abastecimento de água, além da determinação de interações entre variáveis. Quanto à abrangência da pesquisa, pode ser definida como exploratória, já que busca informações e dados de forma a propiciar maior familiarização com o tema em estudo (Sakamoto; Silveira, 2019; Estrela, 2018).

Além disso, a abordagem desta pesquisa classifica o método como hipotético-dedutivo (Severino, 2017), pois houve a elaboração das seguintes hipóteses, no intuito de fomentar a investigação: 1) A existência de planos e políticas de saneamento básico na RMB apresentam um contexto favorável de modo a conduzir as ações de melhorias nos setores? e 2) O nível de cobertura do serviço de abastecimento de água exerce influência significativa sobre os dados relativos aos indicadores epidemiológicos?

\section{2 Área de Estudo}

O estado do Pará abrange 144 municípios, 22 microrregiões e 6 mesorregiões, possui área territorial equivalente a 1.245.870,798 km² e teve a população estimada em 8.690.745 habitantes para o ano de 2020 (IBGE, 2020).

A área de estudo escolhida para esta pesquisa foi a Região Metropolitana de Belém (Figura 1), constituída pelos municípios Ananindeua (1), Belém (2), Benevides (3), Castanhal (4), Marituba (5), Santa Bárbara do Pará (6), e Santa Izabel do Pará (7), sendo integrados em processo de conurbação socioeconômica (SEDOP, 2018). O critério de seleção dessa área de estudo levou em consideração a expressiva densidade populacional e a disponibilidade mais consistente e confiável dos dados em plataformas oficiais.

Figura 1. Região Metropolitana de Belém.

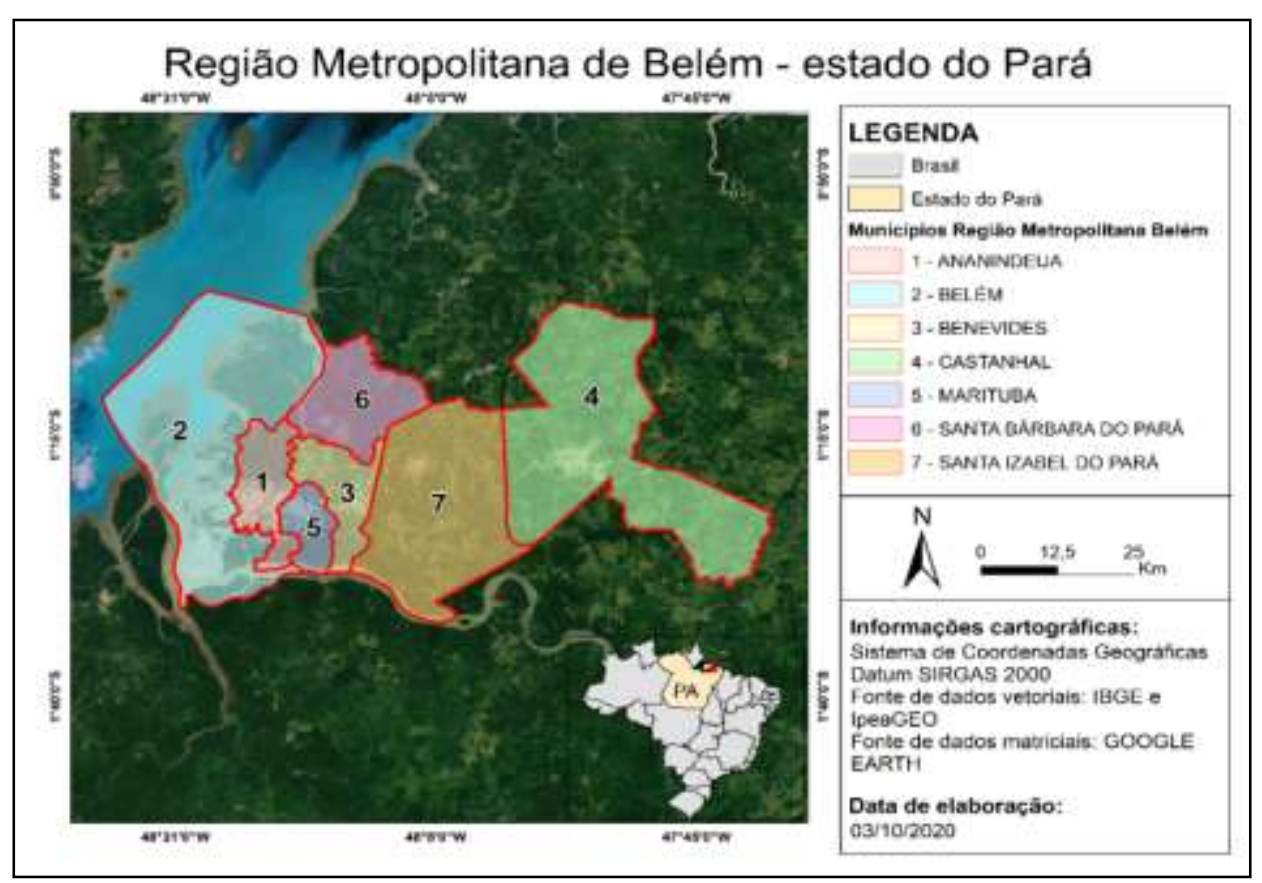

Fonte: Autores (2021). 


\subsection{Coleta de dados}

O estudo consistiu em uma revisão bibliográfica e documental para obtenção de dados secundários. Desse modo, foram contempladas três fases distintas (Figura 2): coleta de dados (Fase I), pré-tratamento de dados (Fase II) e diagnósticos (Fase III).

Figura 2. Esquema da metodologia a ser empregada.

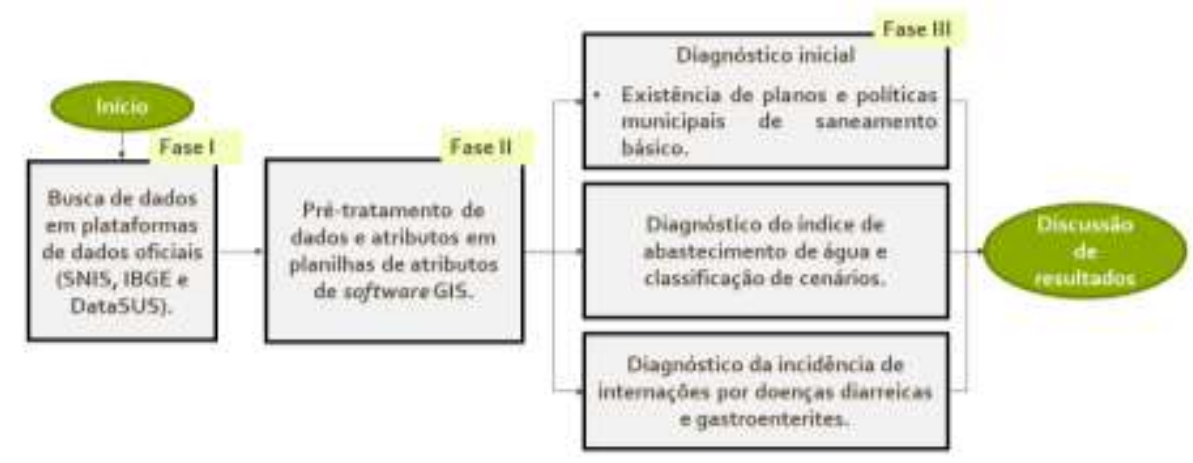

Fonte: Autores (2021).

\subsection{Processamento de dados}

O diagnóstico dos indicadores de abastecimento de água e epidemiológicos foi realizado por meio da busca nas plataformas do Sistema Nacional de Informações sobre Saneamento (SNIS), do Departamento de Informática do Sistema Único de Saúde (DataSUS) e do Instituto Brasileiro de Geografia e Estatística (IBGE). O recorte temporal foi de 2017, 2018 e 2019.

Dessa maneira, a fase III (Figura 2), por sua vez, compreende três etapas de investigação:

1) Diagnóstico inicial, onde foram coletados dados inerentes à existência de planos e políticas municipais de saneamento básico, em 2019;

2) Diagnóstico do índice de abastecimento de água, onde foram coletados dados referentes à população total atendida pelo serviço de abastecimento de água, para que fosse estimado o Índice de População Atendida por Serviços de Abastecimento de Água (IPAag) e, posteriormente, classificados os cenários de abastecimento de água, entre 2017 e 2019;

3) Diagnóstico da incidência de internações por doenças diarreicas e gastroenterites, onde foram coletados dados referentes ao número de internações por doenças diarreicas e gastroenterites de origem presumível e estimada a Incidência de Internações. O critério de seleção se baseou na atenção crescente voltada para essa doença verificada em estudos como o de Dairo, Ibrahim e Salawu (2017), visto os expressivos índices de morbidade e mortalidade.

\section{Resultados e Discussão}

\subsection{Existência de políticas e planos municipais de saneamento básico}

A partir do tratamento dos dados dispostos na plataforma do SNIS, foi possível averiguar os municípios que dispõem de Política Municipal de Saneamento Básico e Plano Municipal de Saneamento Básico, em 2019 (Figura 3). 
Figura 3. Existência de planos e políticas referentes ao setor de saneamento.

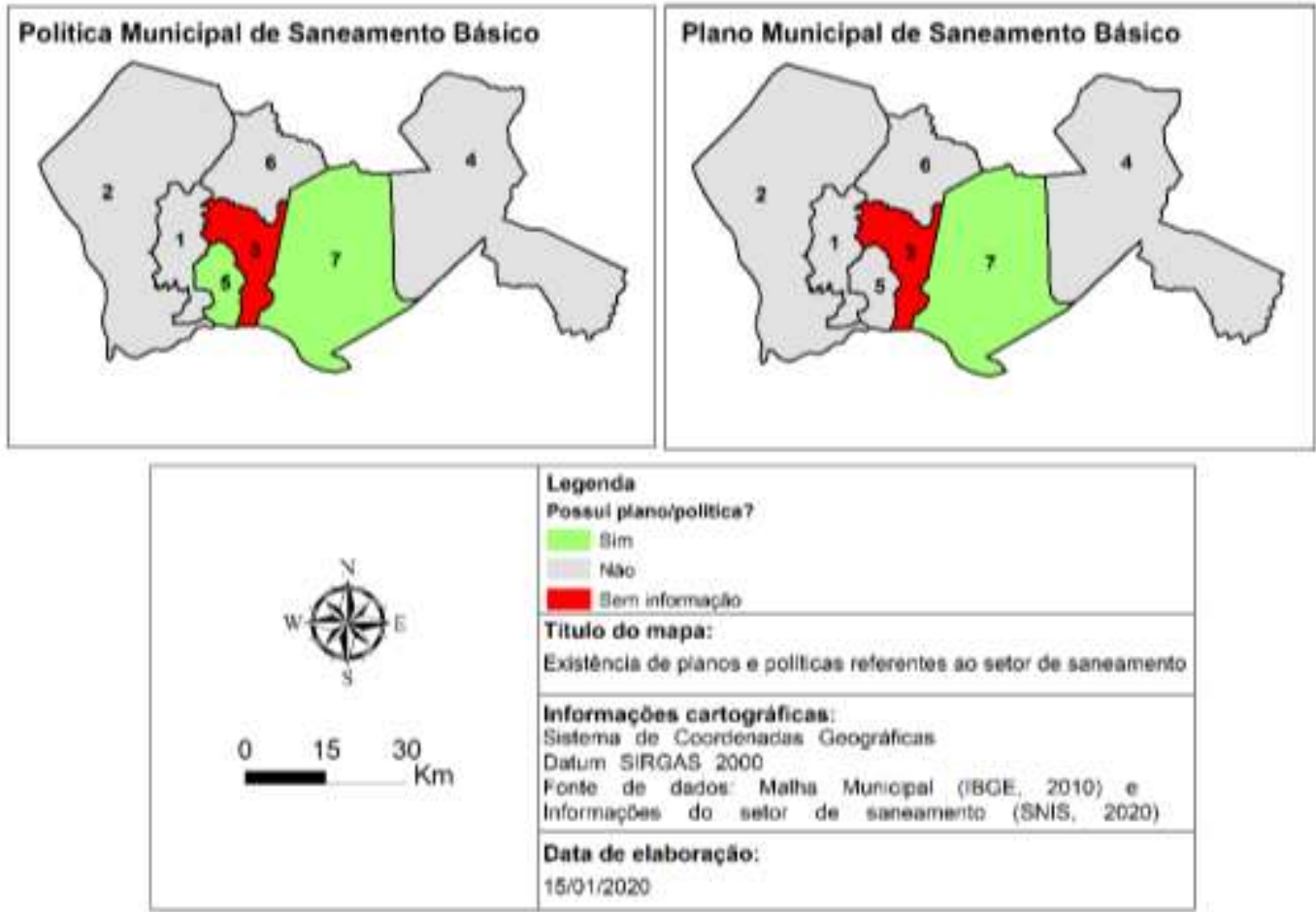

Fonte: Autores (2021).

No que concerne à consolidação da Política Municipal de Saneamento Básico, quatro municípios (n=57,1\%) divulgaram não possuir o documento; dois municípios $(n=28,6 \%)$ afirmaram dispor dela; e um $(n=14,3 \%)$ não divulgou informações sobre o assunto.

A análise dos resultados obtidos permite inferir que a declaração da ausência de política municipal pela maior parte dos municípios pode se apresentar como um entrave à universalização de serviços de saneamento na RMB por dificultar a condução de planejamento e intervenções no setor. Estudo realizado por Nunes e Borja (2019) sobre investimentos em planos municipais de saneamento básico demonstra que a debilidade relativa a esse dispositivo jurídico afeta diretamente a elaboração e qualidade de planos de saneamento básico, visto que eles se subordinam à política.

No que tange à elaboração do Plano Municipal de Saneamento Básico (PMSB), apenas um município (n=14,3\%) apresentou o instrumento; um $(n=14,3 \%)$ não divulgou informações relativas a esse quesito; e 5 municípios (n=71,4\%) não possuem o plano, constituindo a maior parte da RMB.

Visto que a concepção do PMSB é obrigatória a todos os municípios, além de consistir na condição que permite o repasse de recursos da União, conforme a Lei $\mathrm{n}^{\circ}$ 14.026/2020, isso corrobora a ideia do enfrentamento de dificuldades durante a elaboração do documento.

Sobre isso, Lisboa, Heller e Silveira (2013), após realizarem estudo perceptivo dos desafios do planejamento municipal de saneamento básico em pequenos municípios, apontam que as principais dificuldades identificadas estão relacionadas à indisponibilidade de recursos financeiros, à integração de órgãos responsáveis pelo desenvolvimento de serviços pertinentes aos componentes do saneamento, à limitação quanto a qualificação e capacidade técnica dos membros e à vontade política.

Também, vale destacar que, embora os resultados obtidos apontem para a ausência de planos na maior parte de municípios da RMB, estudos aplicados bem como os de

Nunes e Borja (2019), assim como a pesquisa documental realizada nesse estudo, atestam a existência desse documento por parte dos municípios de Belém, Marituba e Castanhal, o que entra em também concordância com a ideia desses autores de 
que a plataforma do SNIS é comprometida pela inconsistência de dados.

\subsection{Panorama de abastecimento de água na RMB e classificação de cenários}

A partir dos dados obtidos na plataforma do SNIS foi possível realizar a análise da evolução de índices de abastecimento de água na RMB referente aos anos de 2017, 2018 e 2019 (Figura 4).

Figura 4. Evolução do índice de abastecimento de água (\%) na RMB - 2017 a 2019.

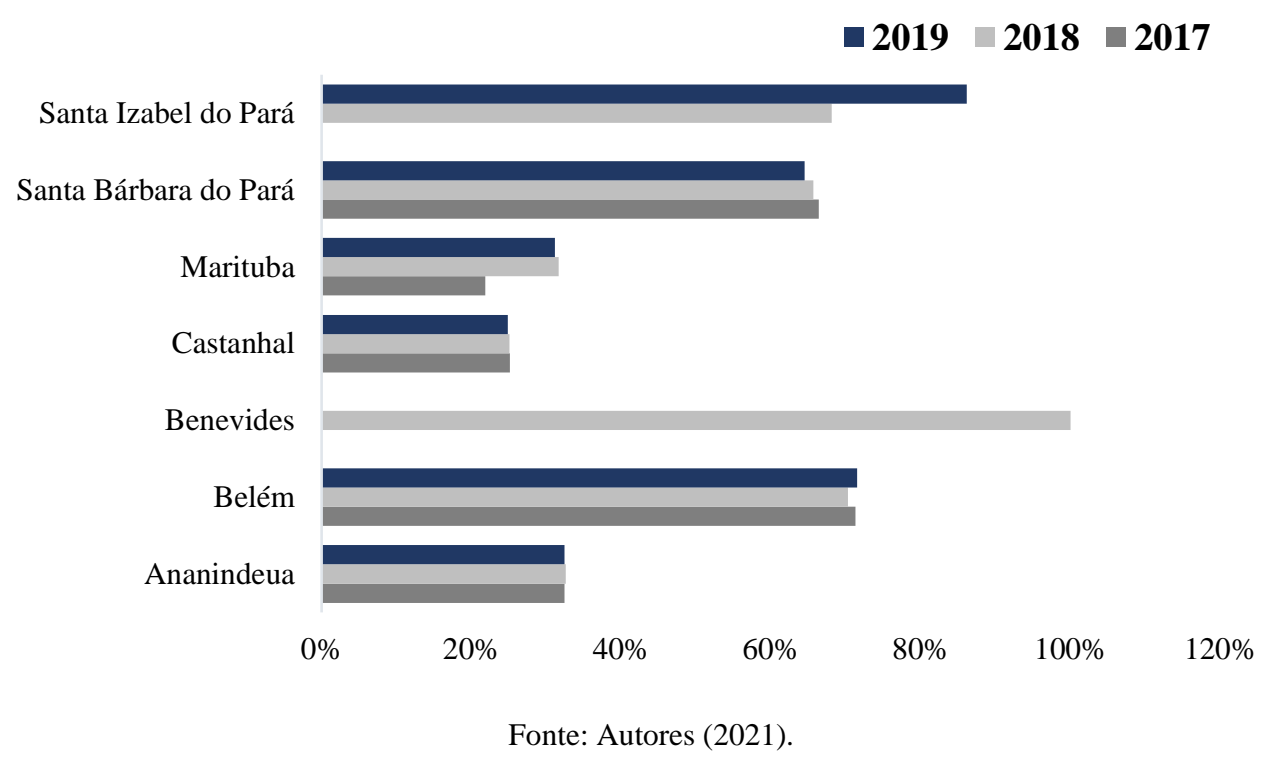

A análise dos dados possibilita deduzir que, em relação ao ano de 2017, as localidades que apresentaram maior e menor índice de abastecimento de água, respectivamente, correspondem a Belém (71,27\%) e Marituba (21,86\%). Nesse ano, os municípios de Benevides e Santa Izabel do Pará não divulgaram informações.

Em 2018, as condições mais favoráveis quanto à cobertura desse serviço foram apresentadas por Benevides (100\%) e as menos favoráveis foram evidenciadas por Castanhal (25,09\%). É válido destacar que, dentre os três anos, apenas no referido, o município de Benevides divulgou informações na plataforma.

No que tange ao ano de 2019, a maior cobertura do serviço foi apresentada por Santa Izabel do Pará $(86,16 \%)$ e a menor foi demonstrada por Castanhal (24,87\%). Nesse período, como já mencionado anteriormente, o município de Benevides foi o único que não dispôs de dados no sistema.

Do mesmo modo foi possível identificar, por meio dessas informações, os cenários de prestação do serviço de abastecimento de água (Figura 5) a partir dos índices de cobertura referentes aos anos de 2017, 2018 e 2019, em conformidade com o preconizado por Silva et al. (2020). 
Figura 5. Evolução do índice de abastecimento de água (\%) - 2017 a 2019.

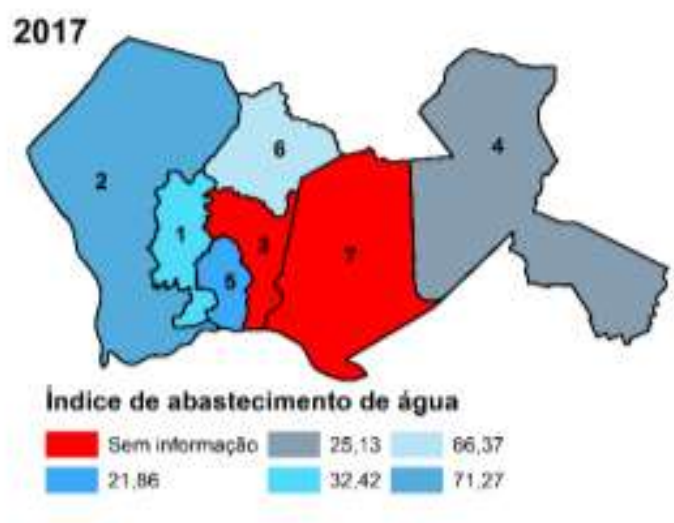

2019

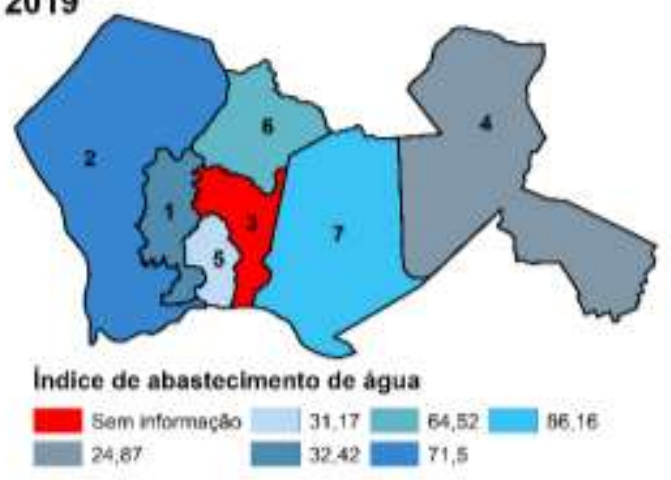

2018

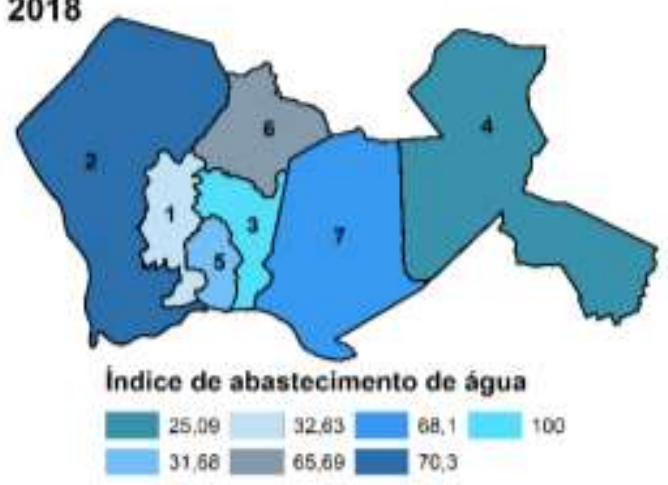

$\begin{array}{cc}\text { Cenário } & \text { Intervalo Percentual } \\ \text { Ruim } & 0 \% \text { a } 49,99 \% \\ \text { Regular } & 50 \% \text { a } 69,99 \% \\ \text { Bom } & 70 \% \text { a } 89,99 \% \\ \text { Muito Bom } & \text { Acima de } 90 \%\end{array}$

Titulo do mapa;

Analise historica do indice de abastecimento agua - 2017 a 2019

Informaçóes cartográficas:

Sistema de Coordenadas Geograficas

Datum SIRGAS 2000

Fonte de dados: Malha Municipal (IBGE, 2010)

informaçes do setor de saneamento (SNIS, 2020)

Data de elaboraçẫo:

$15 / 0212020$

Fonte: Autores (2021).

A análise dos dados obtidos permite inferir que, em relação a Ananindeua, o município possui um cenário ruim de prestação de serviços de abastecimento de água (32,42\%). Isso pôde ser notado não apenas em 2019, mas nos outros dois anos, visto que o valor não sofre grande variações de um período para o outro. De 2017 para 2018, foi observada tendência de elevação nos dados de $0,65 \%$, e, de 2018 para 2019, identificou-se tendência de queda de $0,64 \%$, o que demonstra que quase não houve expansão da cobertura desse serviço.

A partir dos resultados, fica nítida a presença de dificuldades de abastecimento público de água em Ananindeua. Acerca disso, Bordalo (2017), após realizar pesquisa sobre o paradoxo da crise do abastecimento de água na Amazônia brasileira, aborda sobre a grande contradição que envolve essa problemática, uma vez que os municípios que compõem a Região Metropolitana de Belém abrangem considerável disponibilidade hídrica em virtude da grande e rica rede de bacias hidrográficas presentes.

De acordo com informações contidas no Plano Municipal de Saneamento básico de Abastecimento de Água e Esgotamento Sanitário de Belém (Pereira, 2014), o abastecimento de água nos municípios de Belém, Ananindeua e Marituba é feito a partir de: captação hídrica superficial e captação hídrica subterrânea pela Companhia de Saneamento do Pará. O abastecimento contempla 56 setores distintos (19 com água proveniente de manancial superficial e 37 com água advinda de manancial subterrâneo), sendo que apenas Belém e Ananindeua são contemplados com abastecimento de água proveniente de captação hídrica de manancial superficial.

No que diz respeito ao abastecimento de água em Ananindeua, de acordo com o Relatório de Avaliação (CGU, 2018), onde foi feita análise do panorama e do diagnóstico situacional da infraestrutura de Abastecimento de Água na RMB, de todas as contribuições nessa localidade, $35 \%$ são provenientes do tratamento de águas de mananciais superficiais e o restante advém da captação de manancial subterrâneo, por poços profundos. 
Entretanto, como identificado por meio da análise dos dados obtidos, além de não atender satisfatoriamente a demanda social, várias são as denúncias e reclamações acerca de interrupções e falhas do sistema de distribuição de água realizada pela Companhia de Saneamento do Pará (COSANPA). Isto é discorrido em trabalho efetuado por Trindade e Bordalo (2015) sobre indicadores de serviços e rede de abastecimento de água em Belém e Ananindeua.

Nesse sentido, observa-se a gestão ineficaz de recursos hídricos e o descaso de entidades responsáveis na ampliação e melhorias dos serviços de abastecimento de água. Isso corrobora a ideia de Trindade et al. (2017), em pesquisa realizada sobre a gestão do serviço de abastecimento de água na RMB onde Ananindeua é o município enfoque, em que os autores destacam a insuficiente expansão da prestabilidade desse serviço, em decorrência, de forma especial, do carecimento de equipamentos e dispositivos urbanos e o mal gerenciamento de recursos frente à necessidade imediata de investimentos no setor.

No que tange à prestação de serviço de provisão de água relativo a Belém, a análise dos valores obtidos permite concluir que ela constitui um cenário bom $(71,5 \%$ ), sem que também tenham sido identificadas variações expressivas durante os períodos. Entre o ano de 2017 e 2018, notou-se tendência de queda nos valores de aproximadamente 1,36\%, o maior observado entre todos os municípios para esse período, e, entre 2018 e 2019, identificou-se propensão de elevação nos valores de 1,71\%, o que, assim como Ananindeua, demonstra que quase não ocorreu evolução no índice de cobertura desse serviço.

De acordo com o Plano Municipal de Saneamento básico de Abastecimento de Água e Esgotamento Sanitário de Belém (Pereira, 2014), na capital paraense, a principal fonte de abastecimento advém da captação de manancial superficial, sendo 9 setores de abastecimento localizados exclusivamente nesse município (Zona Central), providos por sistemas integrados com unidades de captação, adução, elevação e tratamento. E a segunda fonte é provida por meio de captação subterrânea (Zona de Expansão), os sistemas isolados.

Embora o cenário do município de Belém tenha apresentado situação mais favorável, é importante ressaltar que, a partir dos resultados obtidos, deduz-se que mais de 1/4 da população dessa localidade, por não ter acesso a água da rede pública, acaba por recorrer a outras fontes alternativas de água, muitas vezes pouco salubres.

A respeito disso, estudo realizado por Fenzl, Mendes e Fernandes (2018) acerca da sustentabilidade do sistema de abastecimento de água em Belém, demonstra, por meio da análise de indicadores que buscam mensurar o alcance dos serviços de abastecimento de água nos distritos, que os menos atendidos são notoriamente os mais afastados do centro da cidade, nas áreas periféricas. Esse padrão também foi observado em trabalho feito por Bordalo (2012) sobre a gestão pública dos sistemas de abastecimento de águas na RMB.

Isto se relaciona de forma direta, conforme pesquisa realizada por Araujo et al. (2020), onde os autores fizeram uma análise sobre o processo de urbanização e a aplicação de políticas públicas de lazer em Belém-PA, com o contexto histórico de urbanização desordenada dessa localidade, o que contribuiu para a constituição de bairros desprovidos de infraestrutura básica necessária.

Desse modo, corrobora também o estudo de Carneiro et al. (2018), sobre a perspectiva socioambiental em Belém, ao ser ponderado que essa situação precária de infraestrutura das periferias das cidades é uma dificuldade tipicamente enfrentada por grandes centros urbanos, uma vez que, além do desenvolvimento das cidades ocorrer de forma desordenada, sem seguir as devidas diretrizes de planejamento urbano, a implementação de planos de ação e projetos de investimentos para mitigar essa problemática transcorre de forma lenta e prolongada.

De outra perspectiva, Carvalho e Rocha (2020), ao efetuarem estudo sobre os riscos e a vulnerabilidade socioambiental urbana em Belém-PA, destacam ainda que esse crescimento urbano e demográfico exerce pressão sobre os recursos hídricos, com destaque para o aumento da demanda de água com qualidade adequada, e o impacto ambiental sobre mananciais, visto a geração de efluentes domésticos e industriais e resíduos sólidos. 
No que tange à Marituba, o cenário de abastecimento de água classificado a partir das informações prestadas por essa localidade consiste em ruim (31,17\%). Entre 2017 e 2018, os dados apresentaram a maior tendência de elevação para esse período em comparação a todo o restante de municípios: 46,94\%. Já entre 2018 e 2019, foi averiguada uma tendência de queda pouco significativa de $1,61 \%$ dos valores.

A análise dos dados obtidos demonstra que, mesmo que Marituba tenha apresentado notória evolução nos índices de atendimento de 2017 para 2018, a situação do abastecimento de água no município é precária e urgente. Sobre os sistemas existentes, acordo com dados divulgados pelo Plano Municipal de Saneamento básico de Abastecimento de Água e Esgotamento Sanitário de Belém (Pereira, 2014), os setores de abastecimento de água inseridos no município de Marituba pertencem à Zona de Expansão.

Nesse contexto, Tabosa et al. (2016), em pesquisa sobre o contexto histórico-geográfico da gestão sobre o sistema de abastecimento de água de Belém-PA, e Bordalo (2012) discorrem sobre o não acompanhamento do atendimento público conforme ocorre o crescimento da malha urbana para as áreas distantes da Zona Central.

A respeito dessa expansão, após fazer uma avaliação socioeconômica de quintais urbanos em Marituba-PA, Silva (2019) aborda sobre as dinâmicas de urbanização do espaço e a contribuição da intensa ocupação de áreas periféricas nos déficits de infraestrutura básica.

Isso corrobora o estudo de Rocha (2017) sobre a qualidade das águas subterrâneas do bairro Centro de Marituba-PA, onde a autora ressalta a influência do desordenado, rápido e progressivo adensamento populacional no agravamento de problemas relacionados ao abastecimento de água nesse espaço e manutenção da saúde dos moradores uma vez que a atividade de perfuração de poços sem o adequado controle sanitário tem sido crescente.

Assim, torna-se imprescindível a adoção de medidas de forma a promover evolução na cobertura do atendimento público de abastecimento e a resguardar a saúde e bem-estar social da população de Ananindeua, Belém e Marituba.

Quanto a Benevides, como já anteriormente mencionado, o município foi o que apresentou maior descaso quanto ao preenchimento de dados na plataforma do SNIS, sendo eles dispostos apenas no ano de 2018. Dessa forma, identificou-se um cenário muito bom (100\%) de prestação de serviço de abastecimento de água naquele ano, visto que, embora não tenham sido divulgadas informações nos outros dois anos, foi presumido que não tenha havido grandes mudanças quanto à cobertura de provisão no local, em conformidade com o padrão demonstrado pela maior parte dos demais municípios.

Notou-se que, entre todos os municípios estudados, esse foi o que apresentou o cenário mais favorável. Conforme disposto pelo Plano Diretor do Sistema de Abastecimento de Água da Região Metropolitana de Belém (Pereira, 2006), o serviço de abastecimento de água proveniente de captação de manancial superficial se limita aos municípios de Ananindeua e Belém. Dessa forma, em Benevides, o fornecimento de água é feito por meio de captação hídrica subterrânea de poços tubulares, sob responsabilidade da prefeitura municipal.

Acerca da gestão desse serviços, estudo de Nogueira e Silva (2017), onde a análise partiu da aplicação de Matriz SWOT como diagnóstico da organização dos serviços de abastecimento de água e esgotamento sanitário prestados em Benevides-PA, constata que a entidade responsável, o Serviço de Abastecimento de Água e Esgoto de Benevides (SAEB), "busca sempre uma adequada prestação de serviço e um bom atendimento ao público, sempre buscando integração com outros setores para atingir seus objetivos com transparência e qualidade".

Contudo, de acordo com informações contidas no Relatório de Avaliação (CGU, 2018), os microssistemas de abastecimento de água existentes apresentam falhas e debilidades, uma vez que não passaram por estudos técnicos ideais e devidos projetos de engenharia, o que permite inferir que a população não tem acesso a serviço de qualidade, onde são recorrentes problemas de perdas de água, consumo elevado de energia elétrica, interrupções de provisão etc. Ademais, no documento consta que não foram identificados investimentos públicos estaduais ou federais nesse município naquele ano. 
De forma complementar, em estudo de Vasconcelos Júnior et al. (2018), onde os autores realizaram diagnóstico de qualidade hídrica de poços rasos de um bairro desse município, é possível constatar o grande risco de contaminação atrelado a eles, o que pode afetar de maneira significativa a saúde e bem-estar da população que utiliza esse tipo de fonte de abastecimento.

Ademais, outras pesquisas identificam deficiências no sistema de abastecimento de água, em especial no que diz respeito à qualidade da água fornecida. Como exemplo, em estudo feito por Vieira (2019), onde a autora realiza análise da ocupação das bacias hidrográficas que abrangem o município de Benevides, são abordados problemas no âmbito urbano-ambiental como infraestrutura precária, qualidade ruim da água, desflorestamento, entre outros, em decorrência do uso e ocupação do solo sem planejamento.

A respeito de Castanhal, a partir das informações apresentadas, infere-se que o município apresenta um cenário ruim de prestação de serviço de abastecimento de água (24,87\%). Apesar de os dados terem apresentado tendência de queda ao longo dos anos, a variação a que se refere foi pouco considerável: de 2017 a 2018, foi identificada tendência de queda de 0,16\% e, de 2018 a 2019, foi verificada propensão de queda de $0,88 \%$.

Em comparação ao restante dos municípios da RMB, esse foi o que apresentou o cenário mais desfavorável de atendimento público de água. De acordo com informações contidas no Plano de Saneamento de Castanhal-PA (Castanhal, 2019), o abastecimento de água é realizado por meio de captação hídrica subterrânea, por poços tubulares rasos e profundos, por atuação da COSANPA. Também há a presença de sistemas isolados administrados por particulares e microssistemas da área rural gerenciados pela prefeitura local.

Sobre as dificuldades quanto à cobertura desse serviço, o Relatório de Avaliação da infraestrutura de abastecimento de água na RMB (CGU, 2018) destaca algumas dificuldades de gestão de recursos e risco de carência de recursos para ampliação do sistema de abastecimento de água relativos a atrasos no cumprimento do cronograma físico-financeiro, problemas de projetos básicos deficientes e não aprovação da Caixa Econômica Federal, má gestão na transição de contratos de prestação do serviço, entre outros.

Nesse contexto, esses entraves ocasionam o fraco andamento da expansão desse serviço, em virtude de atrasos no andamento de financiamentos e obras. Em pesquisa de Ferreira (2019), onde o autor realiza estudo de concepção de sistema de abastecimento de água, demonstra que os dados que expõem atendimento público de água limitado indicam que a população utiliza alternativas próprias de abastecimento de água.

No que concerne ao município de Santa Bárbara do Pará, o cenário classificado de prestação de serviços de abastecimento de água foi regular (64,52\%). Embora os valores tenham apresentado apenas tendências de quedas entre os anos, foram níveis de pouca variação: de 2017 a 2018, identificou-se tendência de queda de 1,02\% dos valores, e, de 2018 a 2019, constatou-se tendência de queda de $1,78 \%$, sendo esta última a que representou maior valor, para esse período, em comparação aos demais municípios.

Acerca do atendimento público de água nessa localidade, consta no Relatório de Avaliação (CGU, 2018) que a principal forma de abastecimento de água é proveniente de microssistemas de captação subterrânea, por meio de poços tubulares, ligados diretamente às redes de distribuição, administrados pela prefeitura municipal, visto que a autarquia criada, o SAAESBP - Serviço Autônomo de Água e Esgoto de Santa Bárbara do Pará, apresentou inatividade. Como em Benevides, as obras foram estabelecidas sem o planejamento técnico necessário, com deficiência de projetos de engenharia adequados, o que implica na baixa eficiência da prestação de serviço.

Além disso, o documento expõe que os investimentos para promover a ampliação da infraestrutura dos sistemas de abastecimento de água envolvem recursos direcionados muito abaixo do indispensável para universalização do acesso, assim como não foram verificados quaisquer investimentos em execução que envolvam recursos federais, estaduais e municipais. Isto exige a captação de recursos onerosos e não onerosos da tanto advindos da União quanto do Estado do Pará (CGU, 2018). 
Sobre isso, de acordo com Santos, Kuwajima e Santana (2020), onde eles debatem sobre resultados de estudos e pesquisas em desenvolvimento pelo Instituto de Pesquisa Econômica Aplicada, ressaltam que o problema enfrentado por parte das entidades responsáveis pelo setor de saneamento quanto dificuldades quanto à captação de recursos, investimentos e melhorias, em conjunto com as desigualdades socioeconômicas locais e regionais, gera a carência de serviços e infraestrutura de qualidade, bem como piora da situação socioeconômica na localidade.

Dessa forma, verifica-se a necessidade de aumentar a fonte e alocação de recursos e investimentos no setor de saneamento frente às demandas sempre crescentes, em especial em pequenos municípios, como é o caso de Santa Bárbara. Diante desse tema, Silva (2018), após efetuar estudo sobre investimentos no setor de saneamento no sertão alagoano, destaca também que a disponibilidade de recursos financeiros precisa estar aliada à boa gestão e governança eficiente, em prol do aumento da oferta de serviços.

A análise dos dados obtidos, em relação à Santa Izabel do Pará, permite inferir que esse município apresenta um cenário bom $(86,16 \%)$ de prestação de serviços de abastecimento de água. Não foram disponibilizadas informações no ano de 2017 pela localidade e, entre 2018 e 2019, foi identificada tendência de elevação de 26,52\% nos valores referentes à cobertura desse serviço, o que foi considerada a mais expressiva evolução dentre todos os municípios para esse período.

Sobre a qualidade da prestação do serviço de abastecimento de água nesse município, as informações do Relatório de Avaliação (CGU, 2018) demonstram que os microssistemas de abastecimento de água abrangem a captação subterrânea feita por meio de poços tubulares, ligados diretamente à rede de distribuição, sob responsabilidade da Secretaria de Autônoma de Água e Esgoto - SAAE.

Embora a partir dos dados positivos o município tenha apresentado um panorama razoável de prestação desse serviço, o documento apresenta que, de forma similar aos municípios de Benevides e Santa Bárbara, Santa Izabel sofre com as deficiências infra estruturais dos sistemas existentes, que não foram devidamente planejados e não contaram com o apoio técnico de projetos de engenharia apropriados. Além disso, naquele ano, não foram identificados quaisquer investimentos públicos estaduais ou federais para a promoção de melhorias (CGU, 2018).

Isso corrobora o estudo de Brabo et al. (2014), onde os autores, após realizarem um estudo de avaliação das condições de abastecimento de água no município de Santa Izabel e de elaboração de indicadores de sustentabilidade ambiental, obtiveram resultados negativos para a maior parte deles, dos quais puderam inferir que o sistema opera de forma insatisfatória para a população.

Nesse sentido, também Rodrigues e Rodrigues (2020), em pesquisa sobre as fragilidades socioespaciais no contexto da Amazônia Paraense, destacam que as deficiências relativas à infraestrutura urbana, juntamente com as desigualdade e vulnerabilidade socioespaciais, presentes de forma especial na RBM, são alguns dos fatores resultantes das dinâmicas de ordenamento territorial, e expõem a população a riscos econômicos, sociais e de saúde pública, esse último ligado principalmente à dispersão e dificuldade de controle de doenças.

A fim de obter uma análise sob diferentes aspectos, a partir dos dados obtidos e a classificação de cenários de prestação do serviço de abastecimento de água, foi possível estabelecer as frequências inerentes aos cenários encontrados para cada município da RMB (Tabela 1). 
Tabela 1. Frequências referentes à classificação de cenários de prestação de serviço de abastecimento de água - 2019 .

\begin{tabular}{cccc}
\hline Cenários & Municípios & $\mathbf{f i}$ & $\mathbf{f r}(\mathbf{\%})$ \\
\hline \multirow{2}{*}{ Ruim } & $\begin{array}{c}\text { Ananindeua, Castanhal e } \\
\text { Marituba }\end{array}$ & 3 & 42,9 \\
Regular & $\begin{array}{c}\text { Santa Bárbara } \\
\text { Bom }\end{array}$ & 1 & 14,3 \\
Buito Bom & $\begin{array}{c}\text { Pará } \\
\text { Belém }\end{array}$ & 2 & 28,6 \\
\hline & Benevides & 1 & 14,3 \\
\hline
\end{tabular}

Fonte: Autores (2021).

A média de índice de cobertura de serviço de abastecimento de água foi de 58,66\%, o que representaria um cenário regular, de acordo com Silva et al. (2020). Ressalta-se que se considerou Benevides com índice de cobertura de 100\%, conforme dado apresentado no ano de 2018.

Nesse sentido, ressalta-se que, embora as informações referentes à cobertura do serviço de abastecimento de água disponibilizadas no SNIS sirvam para estabelecer um panorama amplo do quantitativo populacional de atendimento público de água potável, não permite detectar as dimensões, regularidades e fragilidades dos sistemas de abastecimento de água existentes em sua totalidade.

Isto porque a Lei n ${ }^{\circ}$ 14.026/2020, que recentemente atualizou a Política Nacional de Saneamento Básico e que estabelece as diretrizes do saneamento básico no Brasil, no Art. $3^{\circ}$, inciso I-a, define o sistema de abastecimento de água como um conjunto de atividades e manutenção de infraestruturas e instalações operacionais necessárias ao abastecimento público de água potável, com início na captação até as ligações prediais e os respectivos instrumentos de medição (BRASIL, 2020).

Ainda, de acordo com a mesma Lei, Art. $3^{\circ}$-A, os serviços públicos de abastecimento de água à distribuição por intermédio de ligação predial, incluindo eventuais instrumentos de mediação, são: reservação, captação, adução e tratamento de água bruta, e adução e reservação de água tratada (Brasil, 2020).

Já a Portaria de Consolidação $n^{\circ} 5$ do Ministério da Saúde, que consolidou as normas sobre as ações e os serviços de saúde do Sistema Único de Saúde, inclui os padrões de vigilância da qualidade da água para consumo humano e seu padrão de potabilidade, cuja relevância está diretamente ligada à prevenção de quaisquer riscos à saúde humana (Brasil, 2017a).

Dessa forma, faz-se imprescindível que a água distribuída à população atenda ao estabelecido, de forma a satisfazer e promover a manutenção da saúde do usuário. Isto também infere dizer que, embora os dados quantitativos referentes à cobertura do serviço de abastecimento de água demonstrem a fração populacional que usufrui dos serviços da concessionária, não se pode desconsiderar a qualidade operacional e de gestão dos serviços prestados e, principalmente, a qualidade da água que chega aos residentes. Isto é corroborado pelo estudo de Silva e Valentini (2020), em estudo sobre a qualidade da água do abastecimento público no município de Nossa Senhora do Livramento, MT.

Nesse sentido, na Região Metropolitana foi possível verificar dois grandes problemas no que tange ao abastecimento público de água. Primeiramente, o avanço da urbanização e crescimento demográfico, e o consequente aumento da demanda e pressão exercida sobre os recursos hídricos, bem como discorrido por Araújo Júnior, Azevedo e Oliveira (2014) após estudo sobre a problemática concernente à água na RMB.

Também, verifica-se problemas referentes à gestão de serviços de abastecimento de água, bem como falhas de abastecimento, interrupções recorrentes, entre outros. Nesse aspecto, estudo de Ponte et al. (2020), onde autores abordam sobre 
as condições infraestruturais, de moradia e território e a relação com a pandemia do COVID-19, apresenta que, nessa região, a busca por fontes alternativas de abastecimento, tais como o uso significativo de poços que não dispõem licenciamento ambiental e de baixa profundidade, além de denotarem falha no atendimento da entidade responsável, pelo não acesso à rede pública por parte desses moradores, apresentam alto risco de contaminação e podem prejudicar a saúde deles.

Portanto, as condições precárias visualizadas exigem o planejamento e estruturação de projetos que possam envolver futuros investimentos para expansão e melhorias dos sistemas de água existentes, sem desconsiderar a implementação de estratégias de gestão e a adoção de medidas de controle e monitoramento eficazes de uso e ocupação do solo e proteção ambiental, visto que isso influencia diretamente na qualidade da água de mananciais superficiais e subterrâneos.

Acerca disso, Santos, Kuwajima e Santana (2020) destacam a importância do papel do Estado como promotor do saneamento, cabendo a ele a responsabilidade sobre a regulação, financiamento e estipulação de medidas para que sejam sanados os maiores problemas e deficiências das regiões.

Sobre isso, estudo da SEDOP (2018), apresenta a necessidade de integração de ações de planejamento existentes na RMB, como por meio de um plano de desenvolvimento voltado para os municípios que a constituem e todos os pilares do saneamento básico. Da mesma forma, não se restringindo ao planejamento, mas a gestão e a execução devem ser feitas de maneira compartilhada e conjunta por intermédio de auxiliares de cooperação técnica.

Além disso, Santos, Kuwajima e Santana (2020) destacam o aumento das fontes e alocação dos investimentos em capacitação no setor, bem como o aperfeiçoamento das maneiras de subsídios existentes, priorização para destinação de recursos aos municípios que apresentem cenários mais precários de infraestrutura, elaboração e/ou consolidação dos planos de saneamento existentes, coleta de dados para realização de diagnósticos e norteamento de investimentos, entre outros.

Acerca desse tema, também Pauli et al. (2020), após efetuar estudo sobre priorização de investimentos no setor de saneamento com a aplicação de KPIs/Outcomes, destacam que isso requer a alocação assertiva de recursos, para que seja sustentavelmente possível que o município atenda aos objetivos e metas pertinentes a esse planejamento.

Finalmente, França e Nascimento (2020), após realizarem análise de correlação entre indicadores econômicos, de saneamento e de saúde em municípios do estado do Pará, constataram que a avaliação de políticas públicas e revisão de planejamentos com vistas a melhorias constantes, correção de inconformidades e alcance de resultados positivos quanto ao ciclo de gestão, é ferramenta primordial para universalização de acesso ao abastecimento de água e demais componentes do saneamento básico.

\subsection{Relação entre abastecimento de água e indicadores epidemiológicos de doenças diarreicas e gastroenterites}

A partir dos dados disponibilizados pelo DataSUS e SNIS, foi possível identificar os municípios que apresentaram as maiores taxas de incidência de internações (por 10 mil habitantes) por doenças diarreicas e gastroenterites, bem como relacionálas com o cenário de abastecimento de água classificado (Tabela 2), entre 2017 e 2019. 
Tabela 2. Relação entre cenários de abastecimento de água e dados epidemiológicos.

\begin{tabular}{|c|c|c|c|c|c|c|}
\hline \multirow[b]{2}{*}{ Municípios } & \multicolumn{2}{|c|}{2017} & \multicolumn{2}{|c|}{2018} & \multicolumn{2}{|c|}{2019} \\
\hline & $\begin{array}{c}\text { Cenário - } \\
\text { IPAag }\end{array}$ & $\begin{array}{c}\text { Incidência } \\
\text { (por } 10 \text { mil } \\
\text { hab) }\end{array}$ & $\begin{array}{c}\text { Cenário - } \\
\text { IPAag }\end{array}$ & $\begin{array}{c}\text { Incidência } \\
\text { (por } 10 \text { mil } \\
\text { hab) }\end{array}$ & $\begin{array}{c}\text { Cenário - } \\
\text { IPAag }\end{array}$ & $\begin{array}{c}\text { Incidência } \\
\text { (por } 10 \text { mil } \\
\text { hab) }\end{array}$ \\
\hline Ananindeua & Ruim & 10,17 & Ruim & 7,65 & Ruim & 7,27 \\
\hline Belém & Bom & 20,84 & Bom & 18,21 & Bom & 16,04 \\
\hline Benevides & Muito Bom & - & Muito Bom & - & Muito Bom & - \\
\hline Castanhal & Ruim & 13,32 & Ruim & 8,67 & Ruim & 8,91 \\
\hline Marituba & Ruim & 13,69 & Ruim & 17,32 & Ruim & 13,91 \\
\hline Santa Bárbara do Pará & Regular & - & Regular & - & Regular & - \\
\hline Santa Izabel do Pará & Regular & 4,36 & Regular & 3,87 & Bom & 11,16 \\
\hline
\end{tabular}

Fonte: Autores (2021), a partir de SNIS (2019) e DataSUS (2019).

Os municípios de Benevides e Santa barbara do Pará apresentaram ausência de dados disponíveis sobre o quantitativo de casos de internações por doenças diarreicas e gastroenterites na base de dados do DATASUS. Com isso, ficou impossibilitada a realização de análise do panorama de incidência das doenças nesses municípios.

Destaca-se que, no que diz respeito ao município de Benevides, embora ele não tenha disponibilizado dados quanto ao índice de abastecimento de água referente aos anos de 2017 e 2019, foi considerado o percentual apresentado no ano de 2018 (100\%), uma vez que o padrão de variação da maior parte dos demais municípios consiste na pouca diferença quanto a esse índice de um ano para outro.

Do mesmo modo, no que diz respeito ao índice de abastecimento de água do município de Santa Izabel disposto para o ano de 2017, foi utilizado o divulgado no ano seguinte, considerando a variação pouco significativa verificada nas demais localidades e a não divulgação de informações por parte desse município no ano supracitado. Também, Santa Izabel foi o único município que apresentou evolução de cenário de abastecimento de água, saindo de um cenário regular, em 2018, para um cenário bom, em 2019.

No que diz respeito às localidades que apresentaram necessidade de maior atenção quanto aos indicadores epidemiológicos, a análise dos dados permite inferir que os municípios que Belém e Marituba ostentaram as situações mais alarmantes quanto à taxa de incidência de internações por doenças diarreicas e gastroenterites nos três anos estudados.

Respectivamente, os cenários de abastecimento de água desses municípios, nos três períodos, foram: bom e ruim. Além disso, no ano de 2017, o município de Castanhal também apresentou taxa de incidência expressiva e o cenário de cobertura do serviço de abastecimento de água inerente ao município nesse período, bem como nos demais, foi classificado como ruim.

Os resultados obtidos corroboram o estudo de Conde et al. (2013), onde foi feita uma avaliação dos possíveis efeitos na saúde da população da Comunidade Vila da Barca, no município de Belém, PA, decorrentes das condições e intervenções de saneamento ambiental, e, a partir da análise dos dados alcançados, os autores defendem que ao ocorrência de doenças e parasitoses intestinais pode estar associada aos serviços de saneamento precários ou inexistentes, bem como ao inacesso à água de qualidade adequada, à exposição de pessoas a esgotos domésticos não tratados, e também a práticas insuficientes de higiene pessoal e alimentar.

Também, em estudo efetuado por Santos et al. (2018), onde os autores realizam uma análise do panorama do saneamento básico no Brasil e os reflexos na saúde pública, é enfatizada a importância do planejamento e adoção medidas preventivas no combate à disseminação dessas enfermidades hídrica em conjunto com iniciativas de educação sanitária. Nesse contexto, os 
autores afirmam ainda que as dificuldades de universalização de acesso dos municípios brasileiros se relacionam na grande maioria a aspectos financeiros e de cumprimento de metas de regularização da infraestrutura em prazos estipulados.

O panorama concernente aos anos de 2017 a 2019 da RMB traduz um histórico variado sobre a incidência de internações por doenças diarreicas e gastroenterite (Figura 6). Esse histórico possivelmente acompanha a distribuição demográfica desigual em especial dos municípios mais desenvolvidos como os de Belém e Ananindeua, seguidos dos de Castanhal e Marituba.

Figura 6. Evolução da incidência de internações por doenças diarreicas e gastroenterites - 2017 a 2019.
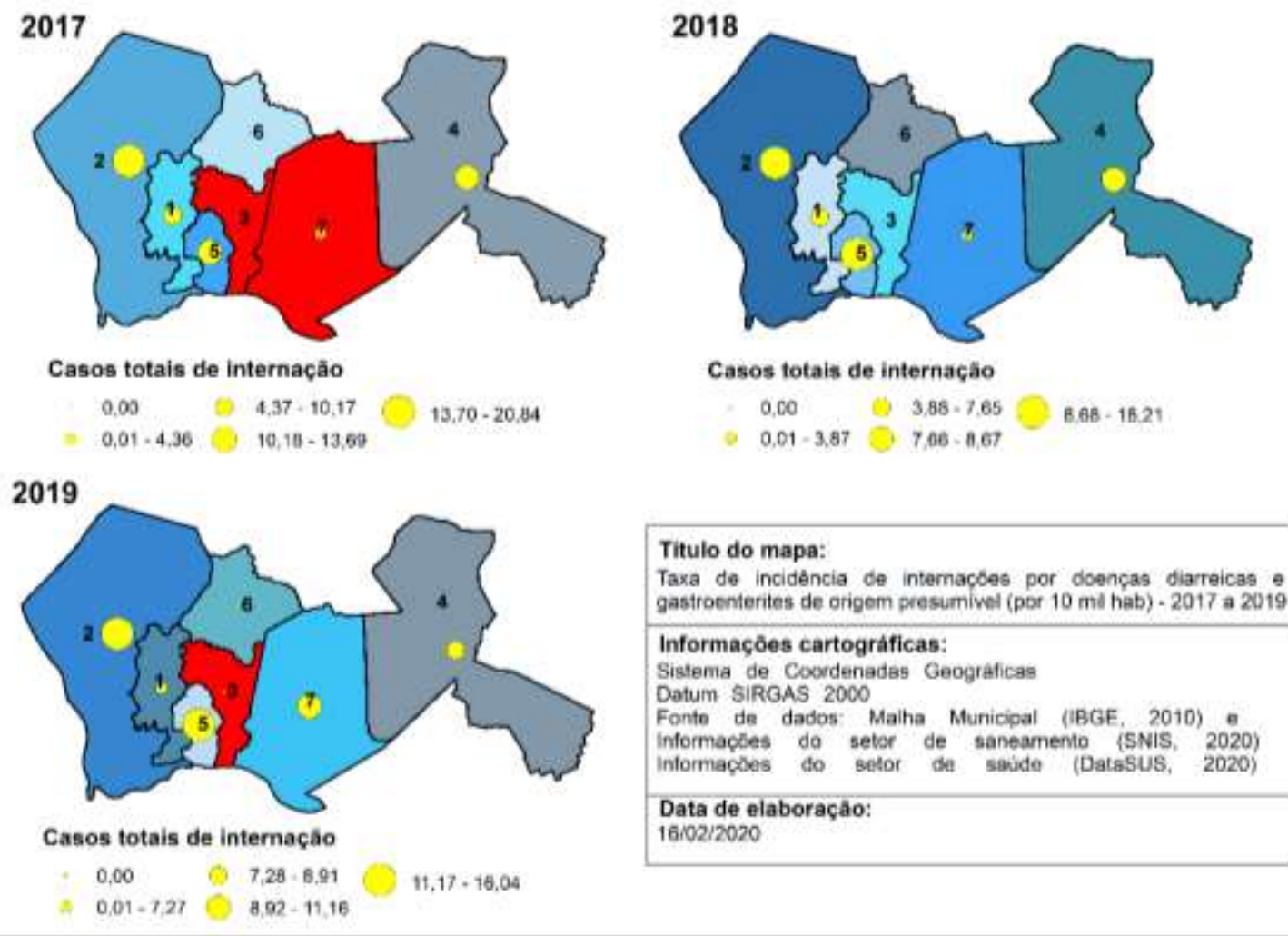

Fonte: Autores (2021).

O município de Ananindeua foi o que apresentou tendência de queda mais expressiva quanto ao número de internações, sendo a tendência de redução da taxa de incidência de internações de 28,5\%, ao se comparar os anos de 2017 e 2019 , ao mesmo tempo em que não houve evolução no que tange ao cenário ruim de abastecimento de água.

Em estudo quantitativo, Pereira e Cabral (2008), ao realizarem uma abordagem para estabelecerem as causas da prevalência significativa de doenças diarreicas agudas em Ananindeua, constaram que o elevado número de casos de internações por estas doenças está diretamente relacionado não apenas com as condições de infraestrutura dos sistemas de saneamento, mas com os dados socioeconômico, culturais e com as condições ambientais.

Visto que o presente estudo discute os dados relativos ao período 2017-2019, passada uma década desde o estudo desses autores, pode-se inferir que, embora o município tenha apresentado evolução favorável no número de internações por doenças diarreicas e gastroenterites, o que pode representar melhoria dos serviços de assistência e saúde pública prestados, esse continua como causa expressiva de internação da população. Dessa forma, não deve ser desconsiderado quando da adoção de medidas de planejamento e intervenções efetivas para melhoria das condições de saneamento básico nesse município.

No que tange aos dados pertinentes a Belém, a incidência da doença apresentou tendências de queda durante o período entre 2017 e 2019, o que representa uma evolução de cerca de 23\% entre o primeiro e o último ano. Ressalta-se que, embora esse município tenha demonstrado situação alarmante quanto à incidência das doenças, como mencionado, durante os três anos 
estudados, o município apresentou também um cenário bom de abastecimento de água. Isso pode ser explicado por fatores socioeconômicos, ineficiência dos sistemas de abastecimento de água e falhas de serviços de assistência e saúde pública da capital paraense.

Com relação às deficiências dos sistemas de abastecimento, estudo de Lima et al. (2018), onde os autores realizam análise de coeficientes de mortalidade e morbidade de doenças relacionadas a saneamento ambiental inadequado em Belém, Pará, mostra que problemas na rede de distribuição e falhas no abastecimento de água, vazões e pressões inadequadas, podem gerar o mau acondicionamento de água tratada, como o armazenamento de água no âmbito domiciliar sem os cuidados necessários, e propiciar o acometimento da saúde pública pela disseminação de doenças.

Além disso, se salienta os riscos inerentes a utilização de fontes alternativas de abastecimento de água para consumo, visto que apenas uma parcela da população tanto de Belém quanto de Ananindeua é provida com água tratada. Isso ocorre em virtude do crescimento urbano sem planejamento desses municípios, o que dificulta a implantação de dutos, equipamentos e ampliação do sistema de forma que atenda à demanda.

A respeito dessa problemática de acesso, Lopes et al. (2017), após efetuar estudo sobre a qualidade da água consumida na Ilha do Mosqueiro, em Belém-PA, inferem que os problemas de gestão e a subsequente incapacidade de atender a população em sua universalidade, implicam na qualidade de vida dos moradores dessa localidade, visto que muitos utilizam água de poços a céu aberto, cujo lençol freático pode estar sendo impactado pelo lançamento de dejetos.

Nesse sentido, pesquisa de Rodrigues, Sander e Wankler (2019) sobre a vulnerabilidade natural do Aquífero Boa Vista, em Boa Vista, Roraima, destaca a relevância do tratamento de esgotos sanitários na prevenção de contaminação de águas subterrâneas, visto que a tendência de crescimento populacional é alta, o que contribui para que seja exercida pressão cada vez maior sobre infraestruturas urbanas.

Já com relação a Marituba, o município apresentou tendência de aumento de 26,5\% na taxa de incidência entre 2017 e 2018, e tendência de queda de 19,7\% entre 2018 e 2019. Concomitantemente, o cenário de abastecimento se manteve ruim durante todo o período.

A principal razão da incidência expressiva pode estar associada ao que foi exposto no PMSB do município (Marituba, 2019): a maior parte da população é abastecida com água proveniente de poços ou nascentes, e, quanto ao esgotamento sanitário, a maior parte da população utiliza fossas rudimentares $(76,4 \%)$.

Segundo Silva (2018), em estudo sobre os reflexos dos investimentos em esgotamento sanitário no sertão de Alagoas, ressalta que o uso generalizado de fossas se constitui numa das principais causas de contaminação da água subterrânea e transtornos do setor de saúde pública na disseminação de doenças diarreicas e gastroenterites.

No que se refere a Castanhal, a maior taxa de incidência de doenças diarreicas e gastroenterites foi observada no primeiro ano do recorte. Posteriormente, em 2018, houve tendência de queda de aproximadamente 35\% e, em 2019, o município apresentou tendência de elevação de cerca de 3\%. Assim como em Ananindeua e Marituba, o cenário permaneceu ruim durante todos os anos analisados.

Novamente, isso pode estar associado ao uso de fontes alternativas inseguras de abastecimento de água no município, principalmente se ele não contar com o serviço de esgotamento sanitário. Isso corrobora o estudo de Rodrigues, Sander e Wankler (2019), visto que o não atendimento público universal de água e o avanço da urbanização somados à falta de sistemas de coleta e tratamento de esgotos sanitários aumentam o risco de contaminação de águas subterrâneas e as chances de disseminação de doenças diarreicas e gastroenterites.

No município de Santa Izabel do Pará, inicialmente, a taxa de incidência de internação por doenças diarreicas e gastroenterites se mostrou consideravelmente baixa em comparação aos demais municípios, apresentando ainda uma tendência 
de diminuição de 11,2\% em 2018. Entretanto, em 2019, foi observada tendência de elevação expressiva de 188\%, aliás, no mesmo período em que o cenário de prestação do serviço de abastecimento de água passou de regular para bom.

Como anteriormente mencionado, o Relatório de Avaliação (CGU, 2018) expõe situações estruturais graves e de bastante precariedade em todas as etapas do abastecimento de água disponibilizada à população. Dessa forma, o conjunto de falhas de gestão desse serviço pode propiciar a busca por outras fontes de provisão de água e o armazenamento de água em ambiente domiciliar, o que expõe a população a riscos de contaminação da água e resulta em surtos infecciosos e adoecimento.

Acerca dessa problemática, Vallim, Santos e Melo (2018) reforçam a relevância do monitoramento da qualidade de águas subterrâneas, bem como iniciativas de educação sanitária para que a população manter as condições adequadas de armazenamento de água nas residências. Além disso, Oliveira et al. (2020) salientam que esse quadro pode ser agravado pela ausência ou ineficácia dos serviços de assistência e atenção básica de saúde.

De forma abrangente, diversos são os fatores que favorecem a ocorrência de diarreias e gastroenterites, os quais podem estar ligados, entre outros, ao tipo de patógeno, condições de saneamento básico, estado imune do hospedeiro e faixa etária. De acordo com Rocha, Rossoni e Faria (2018), as principais medidas para que ocorra uma redução das taxas de incidência de doenças como diarreias e gastroenterites envolvem, especialmente: boa infraestrutura sanitária, abastecimento de água tratada em quantidade e qualidade que satisfaçam as necessidades da população, nutrição alimentar adequada e melhoria na atenção básica de saúde.

Portanto, observa-se a relevância da realização da análise de outros indicadores de saneamento, tais como variáveis socioeconômicas, culturais, investigação de hábitos de higiene pessoal e práticas alimentares, de forma a estabelecer outras relações com os indicadores epidemiológicos.

\section{Conclusão}

Foi identificada a relevância de estabelecer relações entre o abastecimento de água e a incidência de internações por doenças diarreicas e gastroenterites na Região Metropolitana de Belém. Nisto, constatou-se:

- Inconsistência de dados apresentados ao SNIS e déficits quanto à existência de planos e políticas municipais de saneamento básico pela maior parte dos municípios, o que dificulta o planejamento e a condução de ações de melhorias no setor, bem como pode estar associado às falhas de gestão dos serviços;

- Dificuldades de universalização do acesso a serviço de abastecimento de água na RMB, refletidas em cenários desfavoráveis de atendimento público na maioria dos municípios, assim como falhas e ineficiência dos sistemas de abastecimento de água existentes;

- Incidência significativa de internações por doenças diarreicas e gastroenterites, em especial nos municípios de Belém e Marituba, o que pode estar associado aos baixos níveis de cobertura de abastecimento de água, má gestão dos serviços e deficiências dos sistemas existentes.

Também foram identificadas algumas fragilidades e desencontros de informações contidas nos documentos disponíveis nos meios eletrônicos em virtude de alguns estarem desatualizados.

O presente estudo pode auxiliar a tomada de decisões quanto ao planejamento e adoção de medidas de controle e prevenção do agravo epidemiológico. Para estudos vindouros, recomenda-se a investigação de outros indicadores, bem como socioeconômicos, culturais, hábitos alimentares, práticas de higiene pessoal e percepção sanitária, no intuito de estabelecer outras relações e caracterizar outros itens que podem afetar de forma negativa, significativa e direta a saúde e bem-estar da população da RMB. 


\section{Agradecimentos}

À Fundação Amazônia de Amparo a Estudos e Pesquisas (FAPESPA), que financiou a pesquisa.

\section{Referências}

Aguiar, E. S., Ribeiro, M. M., Viana, J. H., \& Pontes, A. N. (2020). Doenças relacionadas ao saneamento ambiental inadequado e indicadores socioeconômicos na Amazônia brasileira. Research, Society and Development, 9(9), e771997302-e771997302.

Albuquerque, D. F., Pessoa, F. C. L., Gomes, E. P., \& Santana, L. R. (2020). Relação entre o abastecimento de água e a ocorrência de doenças em indígenas no estado do Maranhão, Brasil. Research, Society and Development, 9(7), e404974028-e404974028.

JÚNIOR, A. C. R. A., de Azevedo, A. K. A., \& da Silva Oliveira, I. (2014). Problemática Da Água Na Região Metropolitana De Belém (Rmb)-Pará: Aspectos Histórico-Geográficos (Water problem in the Metropolitan Region of Belém (RMB)-Pará: historical and geographical aspects). Acta Geográfica, 7(15), 117131

Araújo, F. E., Anjos, R. S., \& Rocha-Filho, G. B. (2017). Mapeamento participativo: conceitos, métodos e aplicações. Boletim de Geografia, 35(2), 128-140.

Araujo, P. D. S. C. (2019, October). O Direito À Cidade: Interface Entre Urbanização Excludente, Políticas Públicas E Lazer Em Belém Do Pará. In 30 ENAREL Encontro Nacional de Recreação e Lazer e IX Seminário de Estudos do Lazer.

Bordalo, C. A. L., da Cruz Ferreira, C. A., da SILVA, F. A. O., de MORAES, R. C., \& TABOSA, R. K. M. (2012). Os desafios da gestão das águas nas metrópoles da Amazônia: uma análise do modelo de gestão pública dos sistemas de abastecimento de água na região metropolitana de Belém-PA. Geografia Na Amazônia Paraense: Análises Do Espaço Geográfico, 101

Bordalo, C. A. (2017). O paradoxo da água na região das águas: o caso da Amazônia brasileira. GEOUSP Espaço e Tempo (Online), 21 (1), $120-137$.

Brabo, L. D. M., Dutra, V. A. B., Gonçalves, P. V. D. S., Victor, M., \& Campos, A. Abastecimento Público De Água Como Indicador De Sustentabilidade Ambiental: Um Estudo Para O Município De Santa Izabel Do Pará, 2017.

Brasil. Constituição da República Federativa do Brasil. Brasília: Senado Federal, 1988.

Brasil. Doença Diarreica Aguda. Ministério da Saúde, Secretaria de Vigilância em Saúde, Departamento de Vigilância das Doenças Transmissíveis e Coordenação Geral de Doenças Transmissíveis. Brasília: Ministério da Saúde, 2017 b.

Brasil. Lei no 14.026, de 15 de julho de 2020. Atualiza o marco legal do saneamento básico. Diário Oficial da União: Edição: 135, seção 1, Brasília, DF, ano 139 , n. 8 , p. $1-74,2020$

Brasil. Ministério da Saúde. Secretaria de Vigilância em Saúde. Portaria de Consolidação no 05, de 28 de setembro de 2017 . Dispõe sobre os procedimentos de controle e de vigilância da qualidade da água para consumo humano e seu padrão de potabilidade. Diário Oficial da União, Poder Executivo, Brasília, DF, 28 de setembro de $2017 \mathrm{a}$, Seção 2.

Brasil, I. B. G. E. (2018). Instituto Brasileiro de geografia e Estatística.

Brasil, I. B. G. E. (2020). Instituto Brasileiro de geografia e Estatística.

Brasil, T. (2018). Instituto trata brasil. Painel de Saneamento Brasil

Cardoso, P. V., da Silva Seabra, V., Bastos, I. B., \& Costa, E. D. C. P. (2020). A importância da análise espacial para tomada de decisão: um olhar sobre a pandemia de COVID-19. Revista Tamoios, 16(1).

Carneiro, F., Duarte, T., Simões, M. H., \& de Albuquerque Vinagre, M. V. (2018). Saneamento básico: A perspectiva socioambiental na cidade de Belém do Pará. Colóquio Organizações, Desenvolvimento e Sustentabilidade, 9, 427-440.

Carvalho, A. C. L., \& de Miranda Rocha, G. (2020). Análise dos Riscos e da Vulnerabilidade Socioambiental Urbana, face ao Desenvolvimento Desordenado e a Pressão aos Recursos Hídricos em Belém-PA. Brazilian Journal of Development, 6(4), 18127-18142.

Castanhal. Plano Municipal de Saneamento Básico. Castanhal: Prefeitura Municipal de Castanhal, Comitê Executivo e de Coordenação da Elaboração do Plano de Saneamento Básico, 2019. 242 f.

Castro, D. C. C., Rodrigues, R. S. S., \& Ferreira Filho, D. F. (2020). Escoamento superficial na área convergente aos lagos Bolonha e Água Preta em Belém e Ananindeua, Pará. Research, Society and Development, 9(3), e38932373-e38932373.

Catete, C. P. et al. Investigação ambiental e epidemiológica da leptospirose no distrito de Icoaraci, Belém (PA). In: Congresso ABES/Fenasan, 29, 2017, São Paulo. Anais eletrônicos... ABES, 2017.

Conde, G., Chaves, A., Silva, A., Souza, N. P., \& Macedo, Y. S. (2013). Avaliação dos efeitos de projetos de saneamento na saúde da população da Vila da Barca, Belém, Pará. Enciclopédia Biosfera, 9(17).

Controladoria-Geral Da UNIÃO (CGU). Relatório de Avaliação: Exercício 2018. Belém: Ministério das Cidades, 2018.32 f.

Dairo, M. D., Ibrahim, T. F., \& Salawu, A. T. (2017). Prevalence and determinants of diarrhoea among infants in selected primary health centres in Kaduna north local government area, Nigeria. Pan African Medical Journal, 28(1), 151-151. 
Departamento de Informática do Sistema Único de Saúde (DATASUS). Tecnologia da Informação a serviço do SUS. Internações hospitalares do SUS. 2018. 〈http://tabnet.datasus.gov.br/cgi/deftohtm.exe?sih/cnv/sxuf.def〉.

Departamento de Informática do Sistema Único de Saúde (DATASUS). Tecnologia da Informação a serviço do SUS. Internações hospitalares do SUS. 2019. <http://tabnet.datasus.gov.br/cgi/deftohtm.exe?sih/cnv/sxuf.def>.

Estrela, C. (2018). Metodologia científica: ciência, ensino, pesquisa. Artes Médicas.

MendeS, R. L. R., FenzL, N., \& Fernandes, L. L. (2018). A Sustentabilidade do sistema de abastecimento de água: da captação ao consumo de água em Belém.

Ferreira, J. F. H. (2019). Avaliação do consumo e da despesa de energia elétrica no estudo de concepção de sistema de abastecimento de água. (Mestrado em Engenharia Civil) - Instituto de Tecnologia, Universidade Federal do Pará, Belém, 2019.

Ferreira, P. D. S. F., Motta, P. C., de Souza, T. C., da SILVA, T. P., de Oliveira, J. F., \& Santos, A. S. P. (2016). Avaliação preliminar dos efeitos da ineficiência dos serviços de saneamento na saúde pública brasileira. Revista internacional de ciências, 6(2), 214-229.

Freitas Silva, P. R. (2017). A Regionalização Como Expressão Do Livre Arbítrio Nas Institucionalizações Das Regiões Metropolitanas Do Estado De Alagoas. Revista de Geografia (Recife), 34(2).

Souza França, S. A., \& Nascimento, D. M. (2020). Saneamento e Atenção Básica em Municípios do Pará de 2008 a 2017. Brazilian Journal of Development, 6(7), 43689-43405.

Gomes, F. D. (2019). Aspectos do saneamento básico: Brasil e Uruguai. Revista Ciências Jurídicas e Sociais-UNG-Ser, 9(1), 53-58.

Gomes, M. D. C. R., Mendonça, L. A. R., \& Cavalcante, I. N. (2019). Mapeamento da Vulnerabilidade e Risco de Poluição das Águas Subterrâneas na Porção Leste da Bacia Sedimentar do Araripe, Ceará, Brasil. Anuário do Instituto de Geociências, 41(3), 252-259.

Sousa Holanda, C., Lopes, D. L., de Lima Neto, J. B., dos Anjos, V. N., \& Costa, D. R. (2020). Saúde Pública: Relação Entre Fatores Socioeconômicos, Meio Ambiente E Qualidade Da Água. Mostra Científica em Biomedicina, 4(2).

Howard, G., Bartram, J., Williams, A., Overbo, A., Geere, J. A., \& World Health Organization. (2020). Domestic water quantity, service level and health.

Landau, E. C., \& Moura, L. (2016). Variação geográfica do saneamento básico no Brasil em 2010: domicílios urbanos e rurais. Embrapa Milho e Sorgo-Livro técnico (INFOTECA-E).

Leão, L. M. (2019). Metodologia do estudo e pesquisa: facilitando a vida dos estudantes, professores e pesquisadores. Editora Vozes.

Lima, J. S. dos Santos, G. C. S., Rodrigues, R. S. S., \& dos Santos, F. V. (2018). Morbidade e mortalidade por doenças relacionadas ao saneamento ambiental inadequado em Belém do Pará. Ciência E Sustentabilidade, 4(2), 115-132

Lisboa, S. S., Heller, L., \& Silveira, R. B. (2013). Desafios do planejamento municipal de saneamento básico em municípios de pequeno porte: a percepção dos gestores. Engenharia Sanitária e Ambiental, 18, 341-348.

Lopes, R. M., Mesquita, K. F. C., Santos, M. D. L. S., \& Pereira, J. A. R. (2017). Qualidade da água consumida na Ilha do Mosqueiro, Belém-PA. Revista DAE. Maia, I. L. B. (2017). O acesso à água potável como direito humano fundamental no direito brasileiro. Revista do CEPEJ, (20).

Marinho, A. C. D. S. M., Pontes, A. N., \& Bichara, C. N. C. (2020). Saúde ambiental e doenças diarreicas: indicadores socioeconômicos, ambientais e sanitários em um município amazônico. Research, Society and Development, 9(9), e659997803-e659997803.

Marituba. Plano Municipal de Saneamento Básico de Marituba (2019): Produto 3 - Diagnóstico do Saneamento Básico. Marituba: Prefeitura Municipal de Marituba, $347 \mathrm{f}$.

Nogueira, D. H.O.P; Silva, R. A. R (2017). A. A Análise Swot Como Diagnóstico Organizacional No Serviço De Abastecimento De Água E Esgoto Do Município De Benevides-PA. In: CONTECSI - International Conference on Information Systems and Technology Management, Anais... São Paulo.

Nunes, C. R., \& Borja, P. C. (2019). Estimativas De Investimentos Em Planos Municipais De Saneamento Básico: Uma Análise Crítica. Revista Eletrônica de Gestão e Tecnologias Ambientais, 7(1), 122-137.

Oliveira, F. C., Röhnelt, N. M. S., Ritzel, R. G. F., da Silva Heck, T. M., \& Staggemeier, R. (2020). Viroses entéricas: principais patologias de veiculação hídrica e suas manifestações clínicas. Revista Conhecimento Online, 1, 191-217.

Organização das nações Unidas-ONU (2010). The human right to water and sanitation. Resolution Adopted by the General Assembly.

Organização das nações Unidas-ONU (2015). Transforming our world: the 2030 Agenda for Sustainable Development. Resolution Adopted by the General Assembly. Nova York.

Pará. Lei no 8.096, de $1^{\circ}$ de janeiro de 2015. Dispõe sobre a estrutura da Administração Pública do Poder Executivo Estadual, e dá outras providências. Diário Oficial, Belém, $1^{\circ}$ jan. 2015.

Pará. Secretaria de Desenvolvimento Urbano e Obras Públicas (SEDOP). Estudo de delimitação da Região Metropolitana de Belém. Belém: SEDOP, 2018. 172 f.

Pauli, D. R., Simão, M. C., dos Santos, E. F., Reducino, D. T., \& Gava, E.(2020) Priorização De Investimentos Em Saneamento Com A Utilização De Kpis/Outcomes De Contratos De Programa.. In: Congresso Nacional de Saneamento e Meio Ambiente, 31. Anais... Associação dos Engenheiros da Sabesp. 
Silva Peixoto, F., Cavalcante, I. N., Silveira, R. N. C. M., \& da Silva Beserra, F. R. (2017). O Sistema de Informação Geográfica (SIG) Aplicado ao Abastecimento Hídrico e Esgotamento Sanitário. Revista do Departamento de Geografia, 20-28.

Pereira, I. V., \& Cabral, I. E. (2008). Diarreia aguda em crianças menores de um ano: subsídios para o delineamento do cuidar. Escola Anna Nery, 12, $224-229$.

Pereira, J. A. R. (2006). Plano diretor do sistema de abastecimento de água da Região Metropolitana de Belém. Síntese do plano diretor, 100.

Pereira, J. A. R.(2014) Plano Municipal de Saneamento básico de Abastecimento de Água e Esgotamento Sanitário De Belém-Pará volume I concepção técnica e proposições. Secretaria Municipal de Saneamento-SESAN-Belém. 175 f.

Pinheiro, A. D. C. L., \& Ponte, J. P. X. (2021). Identificação e caracterização das relações interfederativas na região metropolitana de Belém: Interfaces com a construção da PNDU: componente A: relatório de pesquisa.

Ponte, J. P. X.(2020). A Região Metropolitana de Belém: territórios precários, condições de infraestrutura, moradia e a Covid-19. Observatório das Metrópoles. $39 \mathrm{f}$.

Rocha, A. C. T., Rossoni, H. A. V., \& da Silva Faria, M. T. (2018). Determinantes envolvidos no perfil de doenças relacionadas às condições sanitárias inadequadas nos municípios brasileiros: avaliação realizada nas 10 melhores e 10 piores cidades do ranking do saneamento. ForScience, 6(2).

Rocha, Á. L. G. D. A. (2017). Qualidade das águas subterrâneas rasas do bairro Centro do município de Marituba-PA e sua relação com as principais fontes potenciais de poluição.

Souza Rodrigues, A., Sander, C., \& Wankler, F. L.(2019). Vulnerabilidade natural à contaminação do Aquífero Boa Vista (ABV) na área urbana de Boa Vista, Roraima. À GEOLOGIA DA AMAZÔNIA.

Rodrigues, J. C., \& Rodrigues, J. C. (2020). Condições De Desigualdades E Vulnerabilidades Socioespaciais Em Cidades Da Amazônia Paraense: Elementos Promovedores Da Expansão E Dispersão Da COVID-19? Hygeia-Revista Brasileira de Geografia Médica e da Saúde, 132-142.

Sakamoto, C. K., \& Silveira, I. O. (2019). Como fazer projetos de Iniciação Científica. Pia Sociedade de São Paulo-Editora Paulus.

Santos, D. T., Berticelli, R., \& Fritsch, R. L. C. (2018). Saneamento básico no Brasil: um importante alicerce na qualidade de vida. Ciência \& Tecnologia, 2(1), $23-43$.

Santos, F. F. S., Daltro Filho, J., Machado, C. T., Vasconcelos, J. F., \& Feitosa, F. R. S. (2018). O desenvolvimento do saneamento básico no Brasil e as consequências para a saúde pública. Revista Brasileira de Meio Ambiente, 4(1).

Santos, G. R. D., Kuwajima, J. I., \& Santana, A. S. D. (2020). Regulação e investimento no setor de saneamento no Brasil: trajetórias, desafios e incertezas.

Severino, A. J. (2017). Metodologia do trabalho científico. Cortez editora

Silva, A. M., \& Valentini, C. M. A. (2020). Reflexões sobre a qualidade da água de abastecimento público em Nossa Senhora do Livramento-MT. Revista Arquivos Científicos (IMMES), 3(2), 1-15.

Silva, D. F., da Costa, G. G. G., Furtado, L. G., Lopes, D. F., \& Lopes, M. D. S. B. (2020). Transparência e universalização dos Índices de Água e Esgoto no Estado do Pará, Brasil. Research, Society and Development, 9(8), e898986341-e898986341.

Silva, G. D. (2018). A efetividade dos investimentos em esgotamento sanitário no sertão alagoano. Trabalho de Conclusão de Curso (Bacharelado em Engenharia Civil) - Unidade Delmiro Gouveia - Campus do Sertão, Curso de Engenharia Civil, Universidade Federal de Alagoas, Delmiro Gouveia.

Silva, J. R. S. D. (2019). Caracterização socioeconômica e ambiental de quintais urbanos em Marituba, Estado do Pará. Orientador: Marcos Antônio Souza dos Santos; Antônia do Socorro Aleixo Barbosa. 2019. 40 f. Trabalho de Conclusão de Curso (Graduação em Agronomia) - Universidade Federal Rural da Amazônia, Campus Belém, PA.

Silva, V. P., da Costa Hianes, A., da Costa Hianes, A., da Costa, M. M., Moura, A. G. A. F., da Costa Duarte, L., \& Catete, C. P. (2019). Mapeamento de pontos de disposição irregular de resíduos sólidos na avenida Bernardo Sayão, em Belém-Pará. Brazilian Journal of Development, 5(12), 31137-31146.

Singh, A. (2019). Remote sensing and GIS applications for municipal waste management. Journal of environmental management, 243, $22-29$.

Soboksa, N. E., Gari, S. R., Hailu, A. B., \& Mengistie Alemu, B. (2021). Childhood Malnutrition and the Association with Diarrhea, Water supply, Sanitation, and Hygiene Practices in Kersa and Omo Nada Districts of Jimma Zone, Ethiopia. Environmental Health Insights, 15, 1178630221999635.

Sistema Nacional de Informações sobre Saneamento-SNIS. (2018). Série Histórica.

Sistema Nacional de Informações sobre Saneamento-SNIS. (2019). Série Histórica.

Tabosa, R., Sombra, D., Leite, A., \& Castro, C. (2016). Revisão histórico-geográfica da gestão pública sobre o sistema de abastecimento hídrico de Belém-PA. InterEspaço: Revista de Geografia e Interdisciplinaridade, 196-220.

Trindade, A. B., Guedes, M. P., Bordalo, C. A. L., \& das Graças Monteiro, N. R. (2017). A gestão do serviço público e abastecimento de água potável na região metropolitana de Belém: o caso do município de Ananindeua-Pará-Brasil. Os Desafios da Geografia Física na Fronteira do Conhecimento, 1, 667-678.

Trindade, A. B., \& Bordalo, C. A. L. (2015). Indicadores Dos Serviços/Rede De Abastecimento De Água Potável Nos Municípios De Belém E AnanindeuaPA: Considerações Para Elaboração Da Cartografia. Revista Nacional de Gerenciamento de Cidades, 3(18). 
Research, Society and Development, v. 10, n. 10, e343101019010, 2021

(CC BY 4.0) | ISSN 2525-3409 | DOI: http://dx.doi.org/10.33448/rsd-v10i10.19010

Vallim, C. A., dos Santos, C. C. A., \& de Melo, E. D. (2018). Correlação Entre Qualidade Da Água E Casos De Diarreia Em Um Município Do Sul De Minas. Semioses, 12(4), 25-37.

Vasconcelos júnior, N. T. et al. (2018). Diagnóstico qualitativo das águas subterrâneas de poços rasos do Bairro das Flores, município de Benevides-PA, a partir da determinação de elementos traços. In: Congresso Brasileiro de Química, 58, 2018, São Luís. Anais... São Luís: Associação Brasileira de Química (ABQ),

Vieira, C. E. (2019). Análise Urbanístico-Ambiental da Ocupação das Bacias Hidrográficas de Benevides (PA). 145 f. Dissertação. (Mestrado em Arquitetura e Urbanismo) - Programa de Pós-graduação em Arquitetura e Urbanismo, UFPA. Pará.

Vieira, J. M. P. (2020). Água e saúde pública: uma perspectiva pós-COVID-19. Revista Eletrônica de Gestão e Tecnologias Ambientais, 8(1), 1-4. 